\title{
Evaluating the relationship between interannual variations in the Antarctic ozone hole and Southern Hemisphere surface climate in chemistry-climate models
}

Article

Accepted Version

Gillett, Z. E., Arblaster, J. M., Dittus, A. J., Deushi, M., Jöckel, P., Kinnison, D. E., Morgenstern, O., Plummer, D. A., Revell, L. E., Rozanov, E., Schofield, R., Stenke, A., Stone, K. A. and Tilmes, S. (2019) Evaluating the relationship between interannual variations in the Antarctic ozone hole and Southern Hemisphere surface climate in chemistry-climate models. Journal of Climate, 32 (11). pp. 3131-3151. ISSN 0894-8755 doi: https://doi.org/10.1175/JCLI-D-18-0273.1 Available at https://centaur.reading.ac.uk/82669/

It is advisable to refer to the publisher's version if you intend to cite from the work. See Guidance on citing.

To link to this article DOI: http://dx.doi.org/10.1175/JCLI-D-18-0273.1

Publisher: AMS

All outputs in CentAUR are protected by Intellectual Property Rights law, 
including copyright law. Copyright and IPR is retained by the creators or other copyright holders. Terms and conditions for use of this material are defined in the End User Agreement.

\section{www.reading.ac.uk/centaur}

\section{CentAUR}

Central Archive at the University of Reading

Reading's research outputs online 
1 Evaluating the relationship between interannual variations in the Antarctic

2 Ozone Hole and Southern Hemisphere surface climate in chemistry-climate

models

4

5 Zoe E. Gillett ${ }^{1,2^{*}}$, Julie M. Arblaster ${ }^{1,2,3}$, Andrea J. Dittus ${ }^{1,4}$, Makoto Deushi ${ }^{5}$, Patrick Jöckel ${ }^{6}$, 6 Douglas E. Kinnison ${ }^{3}$, Olaf Morgenstern ${ }^{7}$, David A. Plummer ${ }^{8}$, Laura E. Revell ${ }^{9,10,11}$, Eugene 7 Rozanov $^{9,12}$, Robyn Schofield ${ }^{13,14}$, Andrea Stenke ${ }^{9}$, Kane A. Stone $^{13,14, \mathrm{a}}$, and Simone Tilmes ${ }^{3}$

${ }^{1}$ School of Earth, Atmosphere and Environment, Monash University, Melbourne, Australia ${ }^{2}$ ARC Centre of Excellence for Climate Extremes, Australia ${ }^{3}$ National Center for Atmospheric Research, Boulder, USA ${ }^{4}$ NCAS-Climate, Department of Meteorology, University of Reading, UK ${ }^{5}$ Meteorological Research Institute, Tsukuba, Japan ${ }^{6}$ Deutsches Zentrum für Luft- und Raumfahrt, Institut für Physik der Atmosphäre, Oberpfaffenhofen, Germany ${ }^{7}$ National Institute of Water and Atmospheric Research, Wellington, New Zealand ${ }^{8}$ Climate Research Branch, Environment and Climate Change Canada, Montreal, Canada ${ }^{9}$ Institute for Atmospheric and Climate Science, ETH Zürich, Zürich, Switzerland ${ }^{10}$ Bodeker Scientific, Christchurch, New Zealand

${ }^{11}$ School of Physical and Chemical Sciences, University of Canterbury, Christchurch, New Zealand ${ }^{12}$ Physikalisch-Meteorologisches Observatorium Davos/World Radiation Center, Davos, Switzerland ${ }^{13}$ School of Earth Sciences, University of Melbourne, Melbourne, Australia 

${ }^{a}$ now at: Massachusetts Institute of Technology, Cambridge, Massachusetts, USA

28 Environment, 9 Rainforest Walk, Monash University, VIC 3800, Australia

29 E-mail: zoe.gillett@monash.edu

30

31

32

33

34

35

36

37

38

39

40

41

42

43

44

45

46

47

48

49 
ABSTRACT

52 Studies have recently reported statistically significant relationships between observed year-toyear spring Antarctic ozone variability and the Southern Hemisphere Annular Mode and surface temperatures in spring-summer. This study investigates whether current chemistry-climate models (CCMs) can capture these relationships, in particular, the connection between November total column ozone (TCO) and Australian summer surface temperatures, where years with anomalously high TCO over the Antarctic polar cap tend to be followed by warmer summers. The interannual ozone-temperature teleconnection is examined over the historical period in the observations and simulations from the Whole Atmosphere Community Climate Model (WACCM) and nine other models participating in the Chemistry-Climate Model Initiative (CCMI). There is a systematic difference between the WACCM experiments forced with prescribed observed sea surface temperatures (SSTs) and those with an interactive ocean. Strong correlations between TCO and Australian temperatures are only obtained for the uncoupled experiment, suggesting that the SSTs could be important for driving both variations in Australian temperatures and the ozone hole, with no causal link between the two. Other CCMI models also tend to capture this relationship with more fidelity when driven by observed SSTs, though additional research and targeted modelling experiments are required to determine causality and further explore the role of model biases and observational uncertainty. The results

69 indicate that CCMs can reproduce the relationship between spring ozone and summer 70 Australian climate reported in observational studies, suggesting that incorporating ozone 71 variability could improve seasonal predictions, however more work is required to understand the difference between the coupled and uncoupled simulations. 


\section{Introduction}

The Antarctic ozone hole has formed each austral spring since the early 1980s where up to half of the total column ozone (TCO) is depleted (Solomon 1999; World Meteorological Organization (WMO) 2014). Though it has little impact on global temperatures, this long-term ozone depletion has likely influenced the Southern Hemisphere (SH) atmospheric circulation and thus the surface climate. It cools the SH polar stratosphere and strengthens the polar vortex; and is associated with a summertime poleward shift and strengthening of the midlatitude jet (Lee and Feldstein 2013; Seviour et al. 2017), strongly associated with the positive phase of the Southern Annular Mode (SAM), the leading mode of climate variability in the SH extratropical circulation (Trenberth 1979; Rogers and van Loon 1982). While increasing greenhouse gases (GHGs) also force a positive summer SAM trend (e.g., Arblaster and Meehl 2006; McLandress et al. 2011; Grise and Polvani 2017), model experiments that have compared the influence of both factors individually have suggested that ozone depletion is likely the dominant factor (e.g., Arblaster and Meehl 2006; McLandress et al. 2011; Polvani et al. 2011; Stone et al. 2016).

In addition to the long-term trend, the size of the ozone hole varies substantially between years due to dynamical processes (Salby et al. 2011, 2012). Years with anomalously small ozone holes are usually associated with stronger winter planetary wave forcing that transports more ozone to the polar region and warms the Antarctic stratosphere, thus weakening the polar vortex. The warmer temperatures inhibit the formation of polar stratospheric clouds that deplete ozone via chemical reactions and hence reduce ozone loss (Salby et al. 2011, 2012). This yearto-year variability in the size of the ozone hole has been linked to variability in the SAM and surface temperatures in the SH. Son et al. (2013) reported a statistically significant negative correlation between September ozone concentration and the October SAM index. Bandoro et al. (2014) further reported a significant relationship between November TCO and seasonal mean summer surface temperatures in the SH midlatitudes, including Australia; with unusually 
hot summers associated with anomalously small ozone holes (higher TCO) in the previous spring. The connection between spring ozone and summer temperature over Australia is thought to arise due to the link between ozone and the SAM. A negative SAM in summer (associated with high spring ozone) causes anomalous westerly surface winds that lead to decreased 103 precipitation and warmer surface temperatures over subtropical eastern Australia in summer 104 (Hendon et al. 2007; Son et al. 2013; Bandoro et al. 2014).

Australian summer temperature extremes are influenced by large-scale modes of climate variability including the El Niño-Southern Oscillation (ENSO), Indian Ocean Dipole and SAM (Hendon et al. 2007; Risbey et al. 2009; Arblaster and Alexander 2012; Min et al. 2013). ENSO has some predictability on seasonal time scales and has, therefore, traditionally

109 been the main component considered in operational seasonal forecasts (McBride and Nicholls 1983) before the implementation of a dynamical seasonal forecast system (Hudson et al. 2016).

111 The observed connection between spring Antarctic ozone and Southern Hemisphere climate 112 suggests that including real-time stratospheric ozone variability could potentially improve skill 113 in seasonal outlook systems. This is particularly timely as extreme summers in Australia are

114 likely to become more common under future emission scenarios (e.g., Perkins et al. 2015;

115 Perkins-Kirkpatrick et al. 2016). Improved seasonal forecasting could, therefore, be an important adaptation tool for mitigating the impacts of extreme heat events. However, climate models must be able to reliably simulate ozone behaviour and 118 stratospheric-tropospheric dynamics to produce accurate forecasts. Chemistry-Climate Models 119 (CCMs) are perhaps the most useful model to address these interactions as chemistry is fully 120 interactive and coupled to dynamics and radiation; and CCMs, therefore, tend to simulate the impacts of ozone on the circulation and climate better than models with prescribed ozone (e.g.,

122 Son et al. 2008; Li et al. 2016). Since chemical reactions cause the ozone hole, it is critical that 
123 interactive chemistry is included in the model to capture and predict these interannual 124 relationships.

125 Many climate model studies have examined the long-term impact of Antarctic ozone 126 depletion on stratospheric and tropospheric circulation and climate (e.g., Gillett and Thompson 127 2003; McLandress et al. 2011; Polvani et al. 2011) but few have addressed the impact on 128 interannual timescales. Fogt et al. (2009) and Li et al. (2010) reported that a CCM captures 129 observed interannual ozone-SAM and SAM-Brewer-Dobson circulation relationships, 130 respectively. However, a deficiency common to these models is related to a "cold pole" bias 131 present in many CCMs (Eyring et al. 2006) which further delays the breakdown of the polar 132 vortex and likely causes the model to overpredict the impacts of the ozone hole (Lin et al. 2017).

133 Moreover, Seviour et al. (2014) reported that the October mean SAM could be forecast from 134 midstratospheric anomalies at the beginning of August, and Dennison et al. (2015) showed that 135 during the period of ozone depletion, the tropospheric circulation is influenced for up to two 136 months following a stratospheric SAM extreme event. To date, there has yet to be a study that 137 has examined whether climate models can simulate the interannual link between ozone and 138 surface temperatures; and hence, the possibility of improving seasonal forecasts.

139 The purpose of the present study is to investigate the potential for predicting summer 140 surface temperature extremes using ozone variability. This involves examining historical 141 simulations from the Whole Atmosphere Community Climate Model (WACCM) and other $142 \mathrm{CCMs}$ to assess whether these models can capture the influence of the interannual variability 143 in the Antarctic spring ozone hole on summer temperatures, with a focus over the Australian 144 continent. This is a necessary first step in examining the potential for its inclusion in a seasonal 145 prediction system. 


\section{Data and analysis method}

148

149

150

151

152

a. Observational and reanalysis data

Multiple observational datasets for TCO and surface temperature are used in this study to examine sensitivity to observation and reanalysis uncertainty. Monthly mean TCO fields have been obtained from the NIWA-BS (National Institute of Water and Atmospheric Research - Bodeker Scientific) database (Bodeker et al. 2005; http://www.bodekerscientific.com/data/total-column-ozone). The NIWA-BS data averaged over the polar cap $\left(63-90^{\circ} \mathrm{S}\right)$, are mainly compared to TCO from the Halley Station (herein Halley) which measures ozone variability at a single grid point $\left(75^{\circ} \mathrm{S}, 26^{\circ} \mathrm{W}\right.$; https://legacy.bas.ac.uk/met/jds/ozone/data/ZOZ5699.DAT). TCO from the South Pole $\left(90^{\circ} \mathrm{S}\right.$, $\left.25^{\circ} \mathrm{W}\right)$ and Syowa $\left(69^{\circ} \mathrm{S}, 39^{\circ} \mathrm{E}\right)$ stations (http://www.woudc.org) are also examined. Monthly mean surface temperatures are obtained from the Interim reanalysis of the European Centre for Medium-Range Weather Forecasts (ERA-Interim; Dee et al. 2011). ERA-Interim is compared to monthly surface temperature from the Australian Water Availability Project (AWAP; Jones et al. 2009) which is a gridded dataset based on station data. Monthly mean maximum and minimum temperatures for AWAP were averaged to produce monthly mean temperature. The Marshall

SAM index (http://www.nercbas.ac.uk/public/icd/gjma/newsam.1957.2007.txt) and ENSO are used to examine links between ozone and modes of climate variability. Gridded observed monthly SSTs from the Hadley Centre Ice and Sea Surface Temperature dataset (Rayner et al. 2003) were used to calculate the Niño 3.4 index (described in Section 2d).

\section{b. Model output}

This study uses the output from version 1 of WACCM, conducted as part of the Chemistry-Climate Model Initiative (CCMI; Eyring et al. 2013). WACCM is a fully interactive 
$172 \mathrm{CCM}$ where chemistry is coupled with dynamics and radiation, and this, therefore, permits 173 chemistry-climate feedbacks. WACCM was chosen as the primary model analysed as it has 174 been shown to have excellent agreement with observations in the evolution of the Antarctic 175 ozone hole (Marsh et al. 2013) and is one of a limited number of CCMs that is coupled to an 176 ocean (Morgenstern et al. 2017), which is an important characteristic for seasonal prediction.

177 The model domain extends from the surface to $140 \mathrm{~km}$ with 66 hybrid sigma-pressure levels, 178 and horizontal resolution of $1.9^{\circ}$ latitude by $2.5^{\circ}$ longitude (Marsh et al. 2013). coupling for stratospheric-tropospheric relationships and the influence of ozone-depleting substances (ODSs) and GHGs individually. Each experiment has an ensemble of three or five transient simulations that have slightly different initial conditions (Eyring et al. 2013; Morgenstern et al. 2017) and cover 1960-2005:

- REF-C1 (or uncoupled): uses an atmosphere-only model configuration forced with observed SSTs and sea ice and historical radiative forcings (GHGs, ODSs, tropospheric ozone and aerosols, quasi-biennial oscillation, very short-lived species, volcanic aerosols, and solar variability)

- REF-C2 (or coupled): uses the identical atmospheric configuration and historical radiative forcings as REF-C1 but is fully coupled to an interactive ocean and sea ice component, and extends to 2100 following the A1 scenario for ODSs (WMO 2014) and Representative Concentration Pathway 6.0 scenario (Meinshausen et al. 2011)

- SEN-C2-fODS1960 (herein ODS1960): the same as REF-C2 but with ODSs containing chlorine and bromine set at 1960 levels. Thus, interannual variations in the size of the Antarctic ozone hole will still occur due to dynamic variability, but no ozone depletion is simulated 
- SEN-C2-fGHG (herein GHG1960): the same as REF-C2 but with anthropogenic GHGs fixed at 1960 levels. otherwise, for consistency, only the first three were used to avoid a larger sample size biasing the results compared to the coupled model ensemble. The other two members were tested and produce quantitatively similar results to the three members used in this study.

To examine the strength of the findings in WACCM and evaluate the impact of model

biases, nine other CCMI models are included (ACCESS-CCM, CESM1 CAM4-Chem, CMAM,

EMAC-L47MA, EMAC-L90MA, GEOSCCM, MRI-ESM, NIWA-UKCA, and SOCOL;

model specifics are available in Morgenstern et al. (2017)). In total, this facilitates analysis of

207 five models with a coupled ocean for REF-C2 and five with an uncoupled ocean that prescribe SSTs and sea ice concentrations using simulations from another climate model. For the CCMs

without an ocean, different SSTs and sea ice concentrations were used for REF-C1 and REF-

C2. All ensemble members available on the British Atmospheric Data Center were included.

For the additional models, the lowest model level was used for the temperature at the surface.

212 We compared the difference between the surface temperature field and lowest model level in the correlation analysis for WACCM, and the difference was negligible.

c. Analysis period

This study examines the period 1979-2005, which represents the overlap period for the satellite data and the model historical period. These years are selected as studies have reported that the relationship between interannual variations in Antarctic ozone and SH surface climate is strengthened during the period of ozone depletion (Fogt et al. 2009; Bandoro et al. 2014) as the ozone hole delays the polar vortex breakdown and leads to increased coupling between the stratosphere and troposphere (Shaw et al. 2011). The Antarctic ozone layer has also shown 
signs of recovery since 2000 (e.g., Solomon et al. 2016; Chipperfield et al. 2017), and the years before this were, therefore, when stratospheric ozone depletion was largest overall. November ozone and summer (December-January-February) surface temperatures are the focus of this study for comparison with Bandoro et al. (2014) and when temperature extremes arguably cause more impact. Ozone variability throughout the year in WACCM is in good agreement with observations and tends to peak in October-November, similar to observations (Table A1; Roff et al. 2011; Son et al. 2013; Bandoro et al. 2014). Apart from Section 3e, all model analysis is conducted for WACCM.

\section{d. Indices}

The ozone hole is defined as the weighted area average TCO over the polar cap (63$90^{\circ} \mathrm{S}$ ), after similar studies (e.g., Son et al. 2013). The ozone index is calculated for September to April only, as observations are unavailable in other months due to polar night. Figure 1a and b show the time series of the ozone index in November for the first member of the WACCM uncoupled and coupled experiments, respectively. The interannual variability of the ozone hole and all indices are obtained by first removing the long-term linear trend (Fig. 1c and d), following Bandoro et al. (2014). Detrending the data also removes the linear influence of GHG 239 increases.

For WACCM, the SAM index is defined as the difference in standardised zonal mean sea level pressure (SLP) between $40^{\circ} \mathrm{S}$ and $65^{\circ} \mathrm{S}$, following Gong and Wang (1999). Strong

242 SAM events are identified when the value is greater or less than one standard deviation (after 243 detrending). The Niño 3.4 index $\left(5^{\circ} \mathrm{S}-5^{\circ} \mathrm{N}\right.$ and $170-120^{\circ} \mathrm{W}$; Trenberth 1997$)$, is used to analyse the ENSO influence on ozone and SAM. 
Pearson correlation coefficients were calculated between ozone and other variables,

248 after first removing the annual cycle and detrending. These links are examined throughout the 249 year using lag correlations, with the ozone index correlated to each 3-month overlapping 250 surface temperature or SAM period for up to 6 months. To explore the relationships further 251 over Australia, we focus on area-averaged surface temperature in Eastern Australia (10-44 ${ }^{\circ} \mathrm{S}$ and $141-156^{\circ} \mathrm{E}$; where at least $50 \%$ of each grid box had to be comprised of land surface to be included in the calculation) as Bandoro et al. (2014) found that the relationship between

254 November ozone and summer surface temperatures was largest in this region. For analysis with WACCM, the three 26-year timeseries from each experiment were concatenated (unless stated otherwise) to provide a larger sample than is possible with the observations and improve the signal-to-noise ratio.

To investigate the influence of large ozone (SAM) anomalies on stratospheric and tropospheric climate, years with high and low November ozone (summer SAM) were identified as years that exceed one standard deviation (after first removing the annual cycle, detrending and concatenating the three members) (Fig. 1c and d). Composites were then created for the difference between years with high and low November ozone (summer SAM). Statistical

263 significance of correlations and composites were assessed using a two-sided Student $t$ test with 264 the degrees of freedom reduced based on the lag-1 autocorrelation, following Bretherton et al. 265 (1999) and Santer et al. (2000).

\section{Results}

\section{a. Ozone-SAM relationship}

The main interest of this paper is the interannual impact of the Antarctic ozone hole on 
(see, e.g., Thompson et al. 2011), the interannual link between ozone and SAM is first explored. Figure 2 shows lag correlations between ozone and SAM (the time reference is based on the ozone index) for Halley ozone $\left(75^{\circ} \mathrm{S}, 25^{\circ} \mathrm{W}\right.$, Fig. 2a), NIWA-BS ozone (averaged $63-90^{\circ} \mathrm{S}$, Fig. $2 \mathrm{~b}$ ) and the four WACCM experiments (averaged $63-90^{\circ} \mathrm{S}$, Fig. $2 \mathrm{c}-\mathrm{f}$ ) where the three ensemble members for each experiment were first concatenated. between spring ozone and SAM in the following months, implying that smaller (larger) spring ozone holes are associated with decreases (increases) in the SAM. This association is consistent with long-term ozone depletion leading to a more positive SAM in summer (Thompson et al. 2011). Though, it is unclear if interannual ozone variations drive variations in the SAM through the same mechanism by which stratospheric ozone depletion influences the SAM, as other factors, such as winter-spring wave driving, also influence SAM and ozone variations (Thompson et al. 2005; Son et al. 2013; Seviour et al. 2014) and it is difficult to separate cause and effect. Note that while we are focussed on the use of ozone for prediction, Fogt et al. (2009) previously found significant negative correlations between observed ozone and SAM also at negative lags, indicating that when the SAM is weak, more ozone is transported to the polar 287 vortex.

There are substantial differences between observational datasets and between model experiments. In the observations, correlations are largest for September-October ozone, whereas the WACCM experiments peak one month later in November-December. A possible cause for the delayed onset in the model experiments could be due to the cold pole bias. For example, Sheshadri and Plumb (2016) found in an idealised atmosphere model that the surface 293 response to polar stratospheric cooling (indicative of ozone depletion) is sensitive to the timing 294 of the cooling. The ozone-SAM link is weaker and less persistent for Halley (Fig. 2a) and could 295 be a consequence of this station being located at the edge of the polar vortex in some parts of 
the year. Both observational datasets and the WACCM coupled and uncoupled experiments capture a band of positive correlations in March-April; which have been linked to natural variability in the polar vortex (Fogt et al. 2009; Smith and Polvani 2017). Furthermore, the SAM response to ozone concentrations seems to be too persistent in the WACCM coupled experiment (Fig. 2d) compared to the atmosphere-only configuration (Fig. 2c), especially in summer.

The differences between the sensitivity and all forcing experiments provide some indications of the forcings driving observed ozone-SAM links. The GHG1960 experiment (Fig. 2e) looks like the all forcing (coupled) experiment, indicating that ozone depletion is the main driver of this interannual relationship. There are still significant correlations when ODSs are fixed at 1960 levels (Fig. 2f), although the correlations are less persistent, suggesting that longterm ozone depletion has increased the strength of the ozone-SAM relationship, as also found by Fogt et al. (2009).

\section{b. Ozone-temperature relationship}

Figure 3 is similar to Fig. 2; however, it shows lag correlations between ozone and

312 Eastern Australia surface temperature. Eastern Australia was chosen for the reference region as

313 the observational study by Bandoro et al. (2014) showed that the correlation between November

314 ozone and summer surface temperatures was largest in this region. The observations capture 315 significant positive correlations between spring ozone months and seasonal Eastern Australia 316 surface temperature; where years with smaller (larger) ozone holes are typically associated with 317 warmer (cooler) temperatures in spring and summer (Fig. 3a-d). Though, as mentioned earlier, 318 this result does not demonstrate causality. It is difficult to separate the roles of the polar vortex, 319 wave-driving and ozone concentrations as they are closely related, however substituting $10 \mathrm{hPa}$ 320 geopotential heights averaged over the polar cap for ozone leads to weaker correlations with 
321 Australian temperature in the model. In complementary results to ours, a recent study by Lim et al. (2018) showed an index of the SH polar vortex is correlated with October and November ozone and with Australian October-January surface temperature.

There are differences between observational datasets, especially when using Halley ozone (Fig. 3a and b), and correlations are less significant overall for AWAP and Halley, compared to ERA-Interim and Halley. A distinct separate band of significant positive correlations is seen for the Halley and ERA-Interim correlations for February ozone (Fig. 3a), which is absent in the other observational correlations. These positive correlations are largest in autumn $(p<0.01)$ and could be related to a trend toward the positive SAM in April-May

330 (Thompson and Solomon 2002; Ivy et al. 2017). As this second band of significant positive 331 correlations is missing for the other datasets, this suggests that there is some uncertainty in the ozone-Australian surface temperature relationship.

333 It is in the link between ozone and surface temperature that noticeable differences

334 between the WACCM experiments begin to appear. The uncoupled experiment captures 335 significant correlations between spring ozone and Eastern Australian surface temperature in the 336 subsequent seasons (Fig. 3e), broadly like the observations, although it peaks slightly later and 337 has significant positive correlations during more months of the year and for longer lags than 338 observed. Studies have found that CCMs tend to overpredict interannual stratosphere339 troposphere relationships due to the polar vortex breaking down later than observed (Fogt et al. 340 2009; Li et al. 2010). This bias may contribute to the overestimated response in the uncoupled 341 experiment (see also Section 3a) and likely has implications for improved seasonal forecasting 342 using ozone. Unlike the uncoupled experiment and observations, the coupled experiment does 343 not capture a significant relationship between spring ozone and spring-summer temperatures 344 (Fig. 3f). 
The WACCM sensitivity experiments again provide some insight as to the forcings contributing most to the ozone and Australian temperature teleconnection. In the GHG1960 experiment (Fig. 3g), there are strong, positive correlations between the year-to-year size of the ozone hole and Eastern Australia surface temperature. These correlations are largest in

349 November but occur for more months in the year than observed, like the uncoupled experiment 350 (Fig. 3e). In the ODS1960 experiment (Fig. 3h), there are weak and insignificant correlations 351 between ozone and surface temperature for most months in the year, similar to the coupled experiment. Thus, the impact of GHGs alone results in a weaker response, consistent with previous results (e.g., Fogt et al. 2009; Bandoro et al. 2014) that suggest that long-term ozone 354 depletion has led to an increase in interannual ozone variability (Table A1) and is, therefore, 355 more able to produce a signal that can influence the surface. The GHG1960 experiment uses 356 the identical configuration to the coupled experiment but with GHGs fixed at 1960 levels. This experiment captures significant correlations between ozone and Eastern Australia surface temperature (Fig. 3g) unlike the all-forcing experiment (Fig. 3f) indicating that the WACCM 359 coupled model can simulate this observed connection, but time-evolving GHGs appear to 360 weaken the relationship. We speculate that this could be related to the interactive impact of 361 increasing GHGs on sea ice and SSTs in this model. For example, similarly to most coupled 362 climate models, Antarctic sea ice extent undergoes large declines over the historical period in 363 the coupled experiment, in contrast to the observed increase over the satellite era (Marsh et al. 364 2013). This decline would likely impact interannual variability in the SAM (e.g., Kidston et al. 365 2011; Raphael et al. 2011) and hence Australian surface temperatures, although this hypothesis 366 requires further investigation with additional models. To provide a global view, surface temperature from ERA-Interim is used for all 368 observational analysis conducted herein. Figure 4 shows the spatial pattern of correlation 369 coefficients of November ozone and summer surface temperatures. These months are examined 
in detail to evaluate whether WACCM can capture the observed link between November ozone 371 and summer temperatures over Australia found by Bandoro et al. (2014). The two observational ozone datasets (Halley and NIWA-BS) have very similar regional structures (Fig. 4a and b), despite differences in the ozone hole definition and data collection method, indicating that the large-scale patterns are mostly unaffected by these factors. In the Australian region, correlations are largest over southern and eastern Australia. The observed correlations for the period 19792004 are not statistically significant over Australia like in the 1979-2012 period (not shown) used by Bandoro et al. (2014), but the pattern is similar.

The WACCM experiments (Fig. 4c and

d) capture similar relationships to the observations over the Antarctica polar cap, regarding sign and magnitude, however, away from this region, there are noticeable differences in the spatial pattern. The uncoupled experiment has more significant correlations in the tropical Pacific and Indian Oceans and tends to simulate stronger correlations overall than observed (Fig. 4c). Notably, both model experiments incorrectly simulate the sign of the correlations over the Indian Ocean and have weaker magnitude over the Southern Ocean. The uncoupled experiment captures strong positive and significant correlations over Australia, with the largest correlations in the south-southeast, consistent with the observations; whereas, the coupled experiment only has low correlations over Australia, as expected from Fig. 3f.

Figure 5 displays the correlation coefficients between November ozone and summer surface temperature in Eastern Australia. For the observations, we compared correlations calculated using Halley and NIWA-BS ozone with TCO from Syowa and South Pole stations (Fig. 5). The relationship is weaker using South Pole ozone and strongest using Syowa ozone instead of Halley ozone, consistent with van Ommen and Morgan (2010) who found a significant relationship between Antarctic snowfall in the Indian Ocean sector and southwest Australian rainfall. The correlations between November ozone and Eastern Australia summer 
surface temperature in the WACCM coupled experiment are weaker overall than the uncoupled experiment and observations (Fig. 5). Using the correlation coefficients for each ensemble member of the WACCM coupled and uncoupled experiments, we conducted an unpaired twosample t-test to assess the significance of the difference of the means. This analysis shows that the difference in the correlation coefficients between the WACCM uncoupled and coupled experiments is statistically significant at the $5 \%$ level.

Figure 5 also shows correlations for the ensemble mean of the WACCM uncoupled and thus helps to isolate the forced response. The ensemble mean correlation is larger than the original correlation in both WACCM experiments, indicating that the forcings (i.e., the historical forcings as well as the SSTs and sea ice in the uncoupled experiment) are enhancing the interannual signal. Given the time series are detrended, it indicates that either some portion of the GHG or ODS forced changes have not been removed through linear regression or that additional forcings are contributing to the interannual relationships found.

Given the ensemble mean of the uncoupled experiment has larger correlations than the 410 individual ensemble members (Fig. 5), this suggests that part of the ozone-temperature 411 relationship is due to the boundary conditions (SSTs and sea ice) driving both interannual 412 variations in ozone and variations in Australian temperature. To test this hypothesis, we 413 subtracted the ensemble mean ozone and Australian temperature from each ensemble member 414 and repeated the calculation with the concatenated ensemble members. This removes the 415 response to the historical forcings and driving SSTs, and the resulting anomalies represent the 416 response to internally generated ozone variations. The correlations were reduced to a similar 417 magnitude as the coupled experiment (Table 1), therefore confirming our hypothesis. coupled model experiment (Fig. 5) since the influence of SSTs will be removed through 
averaging. Given the timeseries are detrended, this points to the role of a non-linear external

421 forcing. Large volcanic eruptions have been shown to impact global mean temperature and

422

423

424

425

426

427

428

430

431

432

434

435

436

437 significantly deplete stratospheric ozone over Antarctica (e.g., McCormick et al. 1995; Solomon et al. 2016; Stone et al. 2017). When the years corresponding to the El Chichón (1982) and Mount Pinatubo (1991) eruptions were removed from the temperature and ozone time series and the ensemble mean was recalculated, in the WACCM coupled experiment, the ensemble mean correlations are substantially reduced (Table 1). This suggests that the impact of these eruptions on the ozone hole and Australian temperatures is reinforced in the ensemble mean and the ozone hole and Australian temperatures are responding to the volcanic forcings. Most of the signal in the uncoupled experiment appears to be coming from the SSTs as the ensemble mean correlations only show minor decreases when the major volcanic eruptions are removed (Table 1).

The WACCM uncoupled experiment appears to have a very strong ENSO response (Fig. 4c), and the summer Niño 3.4 index is significantly correlated with November ozone unlike in the observations or coupled experiment (Table 2). However, strong correlations are still obtained after the ENSO signal is removed from surface temperatures (Table 1), via linear regression against the summer Niño 3.4 index, consistent with the observational study of Bandoro et al. (2014). In the coupled experiment, the relationship between ozone and temperature is strengthened after ENSO is removed from surface temperatures (Table 1).

\section{c. Analysing differences between model experiments}

Section $3 \mathrm{~b}$ demonstrated that a CCM (WACCM) could capture the ozone-temperature teleconnection over Australia, including the observed link between November ozone and summer surface temperature. However, this is not the case for the WACCM coupled experiment, as it only captures weak correlations that are not significant (Figs. 4d and 5). The 
analysis conducted in Section 3c and d, therefore, focuses on understanding why the WACCM coupled experiment cannot capture the observed relationship.

To assess the differences between the WACCM uncoupled and coupled experiments, composites are now used; taking the differences between years with high and low November ozone, defined as years greater than one standard deviation. Figure 6 shows the vertical profile 450 of polar cap geopotential height as a function of month. Higher geopotential heights are 451 observed over Antarctica in years with high ozone (Fig. 6), consistent with the negative phase of the SAM. The difference between the two experiments is largest in the troposphere rather than the stratosphere (tropopause located at approximately $200 \mathrm{hPa}$ over Antarctica). In the uncoupled experiment, stratospheric anomalies appear to be followed by similar signed anomalies in the troposphere, shown by the significant differences between high-low years, and these anomalies reach the surface in late spring to early summer (Fig. 6a). These tropospheric composite differences in December-January are consistent with observations (Thompson and Solomon 2002) where surface anomalies lag stratospheric anomalies by one season, but appear to reach the surface too early in late spring. In the WACCM coupled experiment, there is also 460 downward migration in summer (Fig. 6b); however, it is weaker and not significant. Less 461 downward influence in the coupled experiment could also be related to the somewhat weaker 462 interannual variability in the SAM (Table A2).

Despite the differences shown in Fig. 6, the coupled experiment can simulate the link

464 between ozone and the SAM (Fig. $2 \mathrm{~d}$ and Table 3). Thus, the relationship between ozone and 465 surface temperatures appears to break down in the link between the circulation and 466 temperatures, rather than in the link between ozone and the circulation. Figure 7 shows the difference in the tropospheric and surface response in summer between years with high and low November ozone in the observations. The responses are 469 similar between the Halley and NIWA-BS ozone datasets and ozone hole indices but are weaker 
overall for NIWA-BS. Years with high ozone are associated with easterly wind anomalies over

471 Australian latitudes (Fig. 7c and d), and warmer temperatures across southern-southeastern

472 Australia (Fig. 7a and b), and the SLP field resembles the negative phase of the SAM (Fig. 7e 473 and $\mathrm{f})$.

Figure 8 is like Fig. 7 but for the WACCM uncoupled and coupled experiments. In the uncoupled experiment, years with high November ozone are associated with significant warm anomalies of up to 2 degrees over Australia and a warming of the equatorial Pacific Ocean in summer (Fig. 8a). A strong signal can be seen over the Southern Ocean in the $500 \mathrm{hPa}$ zonal wind in the uncoupled experiment (Fig. 8c), corresponding to an equatorward shift and change in the strength of the $500 \mathrm{hPa}$ midlatitude jet during high ozone years or the negative SAM. In comparison, the coupled experiment does not produce a clear surface temperature difference between high and low ozone years and does not exhibit an ENSO signature (Fig. 8b).

The contrast between the observations and WACCM and the difference between the WACCM uncoupled and coupled experiments is largest in the SLP field (Figs. 7e and $\mathrm{f}$ and 8e and f). In the uncoupled experiment, there is a Pacific South American (PSA) wave train (Karoly 1989). The SAM has been shown to strongly resemble the PSA pattern in the Pacific (Ding et al. 2012) and the PSA is related to ENSO on interannual timescales (Mo 2000), indicating that variability in SSTs in the equatorial central-eastern Pacific is linked to the SAM (i.e., ozone) and may strengthen the link between ozone and Australian temperatures. The uncoupled experiment still produces strong correlations between ozone and Australian temperatures when the ENSO signal is removed (Table 1), despite looking like a typical El Niño response (Fig. 8a and e; Zubiaurre and Calvo 2012), indicating that ozone variability can sufficiently induce changes in the SAM and impact surface temperatures. In contrast, the coupled experiment looks more like zonal wave number 3 (Fig. 8f; Raphael 2004) which alters the wind patterns and temperature response over Australia. Unlike observed (Fig. 7e and f), the 
SAM signal is less distinct in WACCM (Fig. 8e and f). Though, the PSA/ENSO and zonal wave number 3 patterns are linked to the SAM: ENSO and SAM are strongly correlated in the late spring and early summer (e.g., L'Heureux and Thompson 2006; Lim et al. 2013) and the amplitude of wave number 3 is related to the phase of SAM (Turner et al. 2017). The different responses between the uncoupled and coupled experiments could also be related to the ENSO response to ozone being too strong in the uncoupled case (Table 2).

\section{d. Model biases}

A coupled ocean in WACCM appears to change the atmospheric and surface response to interannual ozone variability. The coupled experiment may not capture the observed ozoneAustralian temperatures teleconnection because the evolution of observed SSTs may be crucial to the relationship. Given the ensemble mean of the uncoupled experiment shows a higher correlation coefficient, we suggest that the SSTs could be driving both interannual variations in ozone and Australian temperatures, although, it is likely that the overall ability of a model to reproduce this relationship is also influenced by model biases.

Figure 9 shows the observed and simulated correlations for Eastern Australia summer surface temperatures with SSTs and SLP, respectively. Australian summer surface temperatures are influenced by ENSO, SAM and the Indian Ocean (Fig. 9a and b). The WACCM uncoupled experiment broadly captures these correlations (Fig. 9c and d) in all basins. In the coupled experiment, however, Eastern Australia summer temperatures are dominated by strong anomalies in the tropical Pacific and Indian Oceans (Fig. 9e and f). These tropical model biases may be overwhelming the SAM response and inhibiting the interannual link between ozone and Eastern Australian surface temperatures via the SAM. This is supported by the fact that removing the ENSO signal from surface temperatures in the WACCM coupled experiment (Table 1) slightly increases the strength of the relationship between November ozone and 
summer surface temperature in Eastern Australia. Model biases in the Indian Ocean (e.g., Lim and Hendon 2015) may also result in interference in the surface response in the coupled case. explains up to $22 \%(p<0.01)$ of the interannual variability in Australian temperatures, which is close to the observations where ENSO explains 20\% $(p<0.1)$. However, the influence of ENSO in the coupled experiment is too strong and explains more than $50 \%(p<0.01$, Table 4$)$. The difference between the uncoupled and coupled experiments is highlighted particularly in the impact of SAM on Australian temperatures. While both experiments capture a strong and significant relationship between ozone and SAM (Fig. 2c and d and Table 3), the coupled model

530 poorly simulates the connections between ozone and SAM with Australian temperatures (Figs. 3f, $4 \mathrm{~d}$ and 5 and Table 4). Similar results for the low-top version of the WACCM model (CCSM4; Table 4) indicate that this bias is not related to the inclusion of interactive chemistry or a more resolved stratosphere in WACCM but a likely breakdown in tropical-extratropical 534 interactions in this version of the atmosphere, potentially related to the overestimated magnitude of ENSO (Deser et al. 2012; Marsh et al. 2013). The most recent version of the lowtop model (CESM1-CAM5) has a much-improved relationship between SAM and Australian temperatures (Table 4).

The different SAM responses between the WACCM uncoupled and coupled experiments are further highlighted in Fig. 10, the composite differences in summer between

540 years in the high and low phases of the summer SAM. Over Australia, the positive phase of 541 SAM is associated with cooler temperatures (Fig. 10a) related to the poleward shift of the 542 midlatitude jet (Fig. 10d). The WACCM uncoupled experiment broadly resembles the 543 observations, though with stronger temperature differences over Australia (Fig. 10b). In the 544 coupled experiment, SAM does not appear to make a strong contribution to Australian 
temperatures, shown by the weak temperature differences between high and low SAM (Fig. 10c). The composite temperature differences for the SAM for the coupled experiment also appear to have an ENSO signature (Fig. 10c). Although this warming in the equatorial Pacific

548 Ocean is not significant, it is not seen in the observations or WACCM uncoupled experiment 549 and indicates that ENSO has a strong influence on the SAM during summer in this model 550 experiment. The coupled model SLP composites (Fig. 10i) also indicate positive anomalies in 551 the tropical Indian Ocean and western Pacific Ocean that are not observed and likely interfere with the response to SAM over Australia.

\section{e. Additional models}

Figure 5 also shows the correlation coefficients between November ozone and summer surface temperature in Eastern Australia for the nine additional CCMI models. These models are organised in three groups: CCMI REF-C1, CCMI REF-C2-uncoupled (SSTs and sea ice prescribed from another climate model), and CCMI REF-C2-coupled. Overall, most models capture the correct sign for the correlation between November ozone and summer surface temperatures in Eastern Australia, but there is large intermodel variability in the strength of the correlation coefficients. Unlike in WACCM, there does not appear to be a systematic difference between REF-C1 (uncoupled) and REF-C2 (coupled) for the other models. This suggests that the SSTs might not be primarily driving the response, although they may contribute in part, but

564 rather that model biases are likely impacting most models' ability to reproduce the observed 565 interannual relationship between ozone and Australian summer surface temperature.

\section{Discussion}

This paper is the first to investigate the possibility of predicting seasonal temperatures in Australia with ozone using a climate model. We have demonstrated that a climate model with interactive chemistry can capture observed connections between interannual variability in 
Antarctic TCO and Australian temperatures. Although CCMs are computationally expensive, traditional models that prescribe an ozone climatology can severely underestimate the effects of the ozone hole on climate ( $\mathrm{Li}$ et al. 2016) and will not be able to capture this interannual 574 relationship.

a. Interpretations of discrepancies between observations and models

Section 3 demonstrated that the WACCM REF-C1 (observed SSTs and sea ice) and REF-C2 (coupled ocean) experiments are both able to capture the interannual relationship between ozone and SAM. However, the coupled experiment cannot simulate the interannual relationships between ozone and Australian temperatures and SAM and Australian temperatures, indicating that the relationship breaks down at the surface. Based on the analysis conducted as part of this study, there are currently three plausible interpretations:

(1) That a strong relationship is only seen when the model is forced with observed SSTs suggests that much of the observed signal could be due to the SSTs rather than the Antarctic ozone hole, and the Australian temperatures and ozone hole are simultaneously responding to the SSTs

(2) Model biases might hinder the ability of some climate models to simulate this interannual relationship reliably

(3) Uncertainty in the observations could indicate that the connection between ozone and Australian surface temperatures is not robust and could also be influenced by natural decadal variability.

593 sea ice appear to have an important role in the ozone and Australian temperatures relationship.

594 The results from the WACCM uncoupled experiment are consistent across all ensemble 595 members and increase for the ensemble mean, suggesting that SSTs could be driving variability 
596 in both Australian temperatures and the ozone hole. This hypothesis is supported by the results 597 from REF-C2, where the coupled ocean and freely evolving SSTs and sea ice result in no 598 significant relationship between ozone and Australian temperatures. However, there does not 599 seem to be as clear a difference between REF-C1 and REF-C2 pairs in the four other CCMI 600 models that have an interactive ocean for REF-C2 (Fig. 5), and this hypothesis, therefore, 601 requires further investigation. The second possibility is that the models are unable to represent the key processes necessary to simulate the ozone-temperature relationship correctly. In the WACCM coupled 604 experiment, for example, significant correlations $(p<0.1)$ for November ozone and summer 605 surface temperatures in South-Southeast Australia are only obtained after linearly removing the 606 ENSO signal (not shown) and are still much weaker than observed (Table 1). As noted in 607 Section 3d, the large ENSO amplitude (Deser et al. 2012; Marsh et al. 2013) in the WACCM coupled model may be interfering with the SAM response and impacting the relationship

609 between ozone and surface climate. Furthermore, in the coupled experiment, sea ice is 610 interactive (compared to the uncoupled experiment where it is prescribed from observations); 611 therefore, it is also possible that the coupled model could be influenced by a sea ice feedback 612 (Magnusdottir et al. 2004) that may interfere with the SAM. The preliminary analysis of the 613 fixed GHG experiments (Section 3b) highlights that the coupled model shows an improved 614 simulation of the ozone-surface temperature relationship when the long-term warming 615 associated with increased GHGs is omitted. This suggests that the warming acts to interfere 616 with the interannual variability in ozone and surface climate relationship in the coupled 617 experiment. One hypothesis is that the unrealistic Antarctic sea ice declines and different SST 
618 patterns could push the climate system into a different state to that observed and will be the 619 subject of future work.

The third possibility is that the observed connection between ozone and Australian

621 temperatures is not particularly robust. While Bandoro et al. (2014) reported a statistically

622 significant relationship between November Halley ozone and ERA-Interim summer surface

623 temperatures in Eastern Australia, correlations are largest when these two datasets are used and 624 are weaker or more variable for other combinations. The correlations in this study for the period 625 1979-2004 are also weaker overall than for 1979-2012 (not shown). After 2000 the TCO trend 626 is less negative and even starting to become positive due to initial signs of ozone recovery 627 (WMO 2014; Solomon et al. 2016), although detection of recovery is hindered by limited data 628 records and large atmospheric variability (Chipperfield et al. 2017). Studies have linked the summer positive SAM trend since 2000 to recent changes in SSTs and decadal variability 630 (Pacific decadal oscillation, e.g., Schneider et al. 2015) in addition to ozone depletion and these 631 changes could also be influencing the observed relationship. The possible time-varying nature 632 in the strength of the ozone-temperature connection makes it difficult to compare the 633 observations to model output directly. Further analysis is required to examine the strength and 634 linearity of this relationship and its applicability to additional datasets, to assess whether model 635 results fall within error estimates.

\section{b. Predicting Australian summer temperatures with ozone}

638 This study aimed to examine whether interannual Antarctic spring ozone variability 639 could be used as an indicator of Australian summer surface temperature variability in climate 640 models. To this end, this work has shown that some CCMs can capture the observed relationship 641 between ozone and surface temperatures, and has, therefore, indicated a potential benefit of 642 incorporating ozone variability in seasonal forecasting systems. Operational seasonal 
643 forecasting systems such as the Australian Bureau of Meteorology's seasonal climate forecast 644 system, Predictive Ocean and Atmosphere Model for Australia (POAMA), are coupled but 645 initialised with observed atmosphere and ocean conditions (Lim et al. 2016). Therefore, the 646 ability of some uncoupled models in this study, including WACCM (Fig. 5), to capture a strong 647 relationship between ozone and Australian summer surface temperatures is encouraging to 648 eventually use real-time ozone variability to improve skill in season outlook systems. However, 649 the reliability and accuracy of modelling this relationship is hindered by model biases. Further 650 research to assess model biases will assist in understanding why some models cannot correctly 651 simulate this observed connection with a view to eliminating model biases and eventually 652 improving seasonal prediction.

653 Current operational seasonal forecasting models typically have a poorly resolved 654 stratosphere (Maycock et al. 2011). For example, POAMA only has five levels above $200 \mathrm{hPa}$, 655 and the ozone concentration is set to climatological values (Lim et al. 2016). It may be unable 656 to capture links between the stratosphere and troposphere, and thus, there is a large scope for 657 improving prediction of tropospheric interannual variability. Roff et al. (2011) found that 658 improvements in the stratosphere in a forecasting model, such as a higher stratospheric 659 resolution and better representation of stratospheric dynamics and thermodynamics, led to 660 significant improvements in tropospheric forecast skill. Hence, even if spring Antarctic ozone 661 levels do not prove to be a reliable predictor of SH summer temperature extremes, there is still 662 potential benefit in including time-varying ozone and improving stratospheric representation in 663 operational forecasting systems.

664

5. Conclusions

666

This study examined the ability for WACCM as well as other CCMs to simulate 667 observed links between the spring Antarctic ozone hole and summer surface temperatures over 
668 Australia. A systematic difference is found between the uncoupled and coupled experiments in 669 WACCM and three possible interpretations are provided to explain the discrepancy in 670 simulating the ozone-temperature teleconnection: (1) SSTs play a dominant role and drive 671 interannual variations in both the ozone hole and Australian temperatures, (2) the CCMI models 672 are unable to represent key processes and/or (3) the observed relationship has some uncertainty 673 and is time-varying. While the Australian temperatures and ozone hole may be responding 674 primarily to the SSTs in WACCM, there is some indication that CCMI uncoupled experiments 675 also capture the relationship with more fidelity than the coupled experiments. However, there 676 is not as clear a difference between other coupled and uncoupled experiment pairs amongst the 677 CCMI models, and this hypothesis requires further investigation. It is also possible that the 678 models are unable to capture the observed relationship due to biases, such as in the ENSO amplitude. Furthermore, long-term GHG-induced warming also seems to interfere with the response in the WACCM coupled model. This paper has also highlighted that there is some observational uncertainty regarding the strength of the ozone-temperature teleconnection. The results of this study are encouraging for incorporating ozone variability to improve seasonal predictions, though more work is needed to identify causality in the link between spring ozone and SH surface climate. An experiment that compares the predictive skill in a seasonal forecasting model that is initialised with and without observed ozone would be the next step to demonstrating useful seasonal skill from Antarctic ozone. In addition, targeted

687 modelling experiments which separate the role of SSTs and interannual ozone variations would 688 help to elucidate the mechanism by which ozone impacts the surface climate.

Acknowledgements. 
693 Modeling Program (RGCM) of the U.S. Department of Energy's Office of Biological and 694 Environmental Research (BER) Cooperative agreement DE-FC02-97ER62402 and the

695 National Science Foundation (NSF) as well as the Australian Research Council (ARC) Centre 696 of Excellence for Climate Extremes (CE170100023). Andrea Dittus acknowledges support 697 from the ARC Centre of Excellence for Climate System Science (CE110001028) and the UK 698 National Environment Research Council (NERC) Project SMURPHS (NE/N006054/1). This research was undertaken with the assistance of resources and services from the National Computational Infrastructure, which is supported by the Australian Government. The National Center for Atmospheric Research (NCAR) Command Language (NCL; NCL 2017) was used for data analysis and visualisation.

We acknowledge the modelling groups for making their simulations available for this 704 analysis, the joint WCRP SPARC/IGAC Chemistry-Climate Model Initiative (CCMI) for organising and coordinating the model data analysis activity, and the British Atmospheric Data Centre (BADC) for collecting and archiving the CCMI model output. We acknowledge high707 performance computational support for the WACCM simulations from Yellowstone 708 (ark:/85065/d7wd3xhc) provided by the Climate Simulation Laboratory at NCAR's 709 Computational and Information Systems Laboratory, sponsored by NSF and other agencies. 710 NCAR is funded by NSF. Robyn Schofield and Kane Stone acknowledge support from the 711 ARC Centre of Excellence for Climate System Science (CE110001028), the Australian 712 Government's National Computational Merit Allocation Scheme (q90) and Australian 713 Antarctic science grant program (FoRCES 4012). The EMAC simulations have been performed 714 at the German Climate Computing Centre (DKRZ) through support from the 715 Bundesministerium für Bildung und Forschung (BMBF). DKRZ and its scientific steering 716 committee are gratefully acknowledged for providing the HPC and data archiving resources for 717 the consortial project ESCiMo (Earth System Chemistry integrated Modelling). Eugene 
718 Rozanov acknowledges partial support from the Swiss National Science Foundation under grants 200021169241 (VEC) and 200020182239 (POLE) and the gained information will be used to improve the CCM SOCOL. We also acknowledge Bodeker Scientific, supported

721 722 through the Deep South National Science Challenge, for providing the combined total column ozone database.

We thank Dan Marsh for useful discussions during the course of this study, and three anonymous reviewers whose comments helped to significantly improve the manuscript.

\section{APPENDIX}

\section{Ozone index standard deviation}

\section{APPENDIX B}

\section{SAM index standard deviation}

\section{References}

Arblaster, J. M., and G. A. Meehl, 2006: Contributions of External Forcings to Southern Annular Mode Trends. J. Climate, 19, 2896-2905, doi:10.1175/jcli3774.1.

Arblaster, J. M., and L. V. Alexander, 2012: The impact of the E1 Niño-Southern Oscillation on maximum temperature extremes. Geophys. Res. Lett., 39, 5, doi:10.1029/2012g1053409.

Bandoro, J., S. Solomon, A. Donohoe, D. W. J. Thompson, and B. D. Santer, 2014: Influences of the Antarctic Ozone Hole on Southern Hemispheric Summer Climate Change. J. Climate, 27, 6245-6264, doi:10.1175/JCLI-D-13-00698.1. 
Bodeker, G. E., H. Shiona, and H. Eskes, 2005: Indicators of Antarctic ozone depletion. Atmos. Chem. Phys., 5, 2603-2615.

Bretherton, C. S., M. Widmann, V. P. Dymnikov, J. M. Wallace, and I. Blade, 1999: The effective number of spatial degrees of freedom of a time-varying field. J. Climate, 12, 1990-2009, doi:10.1175/1520-0442(1999)012<1990:tenosd>2.0.co;2.

Chipperfield, M. P., and Coauthors, 2017: Detecting recovery of the stratospheric ozone layer. Nature, 549, 211-218, doi:10.1038/nature23681.

Dee, D. P., and Coauthors, 2011: The ERA-Interim reanalysis: configuration and performance of the data assimilation system. Quart. J. Roy. Meteor. Soc., 137, 553-597, doi:10.1002/qj.828.

Dennison, F. W., A. J. McDonald, and O. Morgenstern, 2015: The effect of ozone depletion on the Southern Annular Mode and stratosphere-troposphere coupling. J. Geophys. Res., 120, 6305-6312, doi:10.1002/2014jd023009.

Deser, C., and Coauthors, 2012: ENSO and Pacific Decadal Variability in the Community Climate System Model Version 4. J. Climate, 25, 2622-2651, doi:10.1175/jcli-d-1100301.1.

Ding, Q. H., E. J. Steig, D. S. Battisti, and J. M. Wallace, 2012: Influence of the Tropics on the Southern Annular Mode. J. Climate, 25, 6330-6348, doi:10.1175/jcli-d-1100523.1.

Eyring, V., and Coauthors, 2006: Assessment of temperature, trace species, and ozone in chemistry-climate model simulations of the recent past. J. Geophys. Res., 111, D22308, doi:10.1029/2006jd007327. 
Eyring, V., and Coauthors, 2013: Overview of IGAC/SPARC Chemistry-Climate Model Initiative (CCMI) community simulations in support of upcoming ozone and climate assessments. SPARC Newsletter, 40, 48-66.

Fogt, R. L., J. Perlwitz, S. Pawson, and M. A. Olsen, 2009: Intra-annual relationships between polar ozone and the SAM. Geophys. Res. Lett., 36, L04707, doi:10.1029/2008g1036627.

Gillett, N. P., and D. W. J. Thompson, 2003: Simulation of Recent Southern Hemisphere Climate Change. Science, 302, 273-275, doi:10.1126/science.1087440.

Gong, D., and S. Wang, 1999: Definition of Antarctic Oscillation index. Geophys. Res. Lett., 26, 459-462, doi:10.1029/1999GL900003.

Grise, K. M., and L. M. Polvani, 2017: Understanding the Time Scales of the Tropospheric Circulation Response to Abrupt CO2 Forcing in the Southern Hemisphere: Seasonality and the Role of the Stratosphere. J. Climate, 30, 8497-8515, doi:10.1175/jcli-d-16-0849.1.

Hendon, H. H., D. W. J. Thompson, and M. C. Wheeler, 2007: Australian rainfall and surface temperature variations associated with the Southern Hemisphere annular mode. $J$. Climate, 20, 2452-2467, doi:10.1175/jcli4134.1.

Hudson, D., A. G. Marshall, O. Alves, G. Young, D. Jones, and A. Watkins, 2016: Forewarned is Forearmed: Extended-Range Forecast Guidance of Recent Extreme Heat Events in Australia. Wea. Forecasting, 31, 697-711, doi:10.1175/waf-d-150079.1. 
Ivy, D. J., C. Hilgenbrink, D. Kinnison, R. A. Plumb, A. Sheshadri, S. Solomon, and D. W. J.

785

786

787

788

789

790

791

792

793

794

795

796

797

798

799

800

801

802

803

804

805 Thompson, 2017: Observed Changes in the Southern Hemispheric Circulation in May. J. Climate, 30, 527-536, doi:10.1175/jcli-d-16-0394.1.

Jones, D. A., W. Wang, and R. Fawcett, 2009: High-quality spatial climate data-sets for Australia. Aust. Meteor. Oceanogr. J., 58, 233-248.

Karoly, D. J., 1989: Southern Hemisphere Circulation Features Associated with El NiñoSouthern Oscillation Events. J. Climate, 2, 1239-1252, doi:10.1175/15200442(1989)002<1239:shcfaw $>2.0 . c 0 ; 2$.

Kidston, J., A. S. Taschetto, D. W. J. Thompson, and M. H. England, 2011: The influence of Southern Hemisphere sea-ice extent on the latitude of the mid-latitude jet stream. Geophys. Res. Lett., 38, 5, doi:10.1029/2011g1048056.

L'Heureux, M. L., and D. W. J. Thompson, 2006: Observed relationships between the El Niño-Southern Oscillation and the extratropical zonal-mean circulation. J. Climate, 19, 276-287, doi:10.1175/jcli3617.1.

Lee, S., and S. B. Feldstein, 2013: Detecting Ozone- and Greenhouse Gas-Driven Wind Trends with Observational Data. Science, 339, 563-567, doi:10.1126/science.1225154.

Li, F., P. A. Newman, and R. S. Stolarski, 2010: Relationships between the Brewer-Dobson circulation and the southern annular mode during austral summer in coupled chemistry-climate model simulations. J. Geophys. Res., 115, 12, doi:10.1029/2009jd012876.

Li, F., Y. V. Vikhliaev, P. A. Newman, S. Pawson, J. Perlwitz, D. W. Waugh, and A. R. Douglass, 2016: Impacts of Interactive Stratospheric Chemistry on Antarctic and 
806

807

808

809

810

811

812

813

814

816

817

818

819

820

821

822

823

824

825

826

827

Southern Ocean Climate Change in the Goddard Earth Observing System, Version 5 (GEOS-5). J. Climate, 29, 3199-3218, doi:10.1175/jcli-d-15-0572.1.

Lim, E.-P., H. H. Hendon, and H. Rashid, 2013: Seasonal Predictability of the Southern Annular Mode due to Its Association with ENSO. J. Climate, 26, 8037-8054, doi:10.1175/jcli-d-13-00006.1.

Lim, E.-P., and H. H. Hendon, 2015: Understanding the Contrast of Australian Springtime Rainfall of 1997 and 2002 in the Frame of Two Flavors of El Niño. J. Climate, 28, 2804-2822, doi:10.1175/jcli-d-14-00582.1.

Lim, E.-P., H. H. Hendon, D. Hudson, M. Zhao, L. Shi, O. Alves, and G. Young, 2016: Evaluation of the ACCESS-S1 hindcasts for prediction of Victorian seasonal rainfall. Bureau Research Report, 19.

Lim, E. P., H. H. Hendon, and D. W. J. Thompson, 2018: Seasonal Evolution of StratosphereTroposphere Coupling in the Southern Hemisphere and Implications for the Predictability of Surface Climate. J. Geophys. Res., 123, 12,002-12,016, doi:10.1029/2018JD029321.

Lin, P., D. Paynter, L. Polvani, G. J. P. Correa, Y. Ming, and V. Ramaswamy, 2017: Dependence of model-simulated response to ozone depletion on stratospheric polar vortex climatology. Geophys. Res. Lett., 44, 6391-6398, doi:10.1002/2017g1073862.

Magnusdottir, G., C. Deser, and R. Saravanan, 2004: The effects of North Atlantic SST and sea ice anomalies on the winter circulation in CCM3. Part I: Main features and storm track characteristics of the response. J. Climate, 17, 857-876, doi:10.1175/15200442(2004)017<0857:teonas $>2.0$. co;2. 
828 Marsh, D. R., M. J. Mills, D. E. Kinnison, J.-F. Lamarque, N. Calvo, and L. M. Polvani,

829

830

831

832

833

834

835

836

837

838

839

840

841

842

843

844

845

846

847

848 2013: Climate Change from 1850 to 2005 Simulated in CESM1(WACCM). $J$. Climate, 26, 7372-7391, doi:10.1175/jcli-d-12-00558.1.

Marshall, G. J., 2003: Trends in the Southern Annular Mode from Observations and Reanalyses. J. Climate, 16, 4134-4143, doi:10.1175/15200442(2003)016<4134:titsam>2.0.co;2.

Maycock, A. C., S. P. E. Keeley, A. J. Charlton-Perez, and F. J. Doblas-Reyes, 2011: Stratospheric circulation in seasonal forecasting models: implications for seasonal prediction. Climate Dyn., 36, 309-321, doi:10.1007/s00382-009-0665-x.

McBride, J. L., and N. Nicholls, 1983: Seasonal Relationships between Australian Rainfall and the Southern Oscillation. Mon. Wea. Rev., 111, 1998-2004, doi:10.1175/15200493(1983)111<1998:SRBARA>2.0.CO;2.

McCormick, M. P., L. W. Thomason, and C. R. Trepte, 1995: Atmospheric effects of the Mt Pinatubo eruption. Nature, 373, 399-404, doi:10.1038/373399a0.

McLandress, C., T. G. Shepherd, J. F. Scinocca, D. A. Plummer, M. Sigmond, A. I. Jonsson, and M. C. Reader, 2011: Separating the Dynamical Effects of Climate Change and Ozone Depletion. Part II: Southern Hemisphere Troposphere. J. Climate, 24, 18501868, doi:10.1175/2010jcli3958.1.

Meinshausen, M., and Coauthors, 2011: The RCP greenhouse gas concentrations and their extensions from 1765 to 2300. Climatic Change, 109, 213, doi:10.1007/s10584-0110156-z. 
Min, S. K., W. Cai, and P. Whetton, 2013: Influence of climate variability on seasonal extremes over Australia. J. Geophys. Res., 118, 643-654, doi:10.1002/jgrd.50164.

Mo, K. C., 2000: Relationships between low-frequency variability in the Southern Hemisphere and sea surface temperature anomalies. J. Climate, 13, 3599-3610, doi:10.1175/1520-0442(2000)013<3599:rblfvi>2.0.co;2.

Morgenstern, O., and Coauthors, 2017: Review of the global models used within phase 1 of the Chemistry-Climate Model Initiative (CCMI). Geosci. Model Dev., 10, 639-671, doi:10.5194/gmd-10-639-2017.

Perkins, S. E., D. Argueso, and C. J. White, 2015: Relationships between climate variability, soil moisture, and Australian heatwaves. J. Geophys. Res., 120, 8144-8164, doi:10.1002/2015jd023592.

Perkins-Kirkpatrick, S. E., and Coauthors, 2016: Natural hazards in Australia: heatwaves. Climatic Change, 139, 101-114, doi:10.1007/s10584-016-1650-0.

Polvani, L. M., D. W. Waugh, G. J. P. Correa, and S. W. Son, 2011: Stratospheric Ozone Depletion: The Main Driver of Twentieth-Century Atmospheric Circulation Changes in the Southern Hemisphere. J. Climate, 24, 795-812, doi:10.1175/2010jcli3772.1.

Raphael, M. N., 2004: A zonal wave 3 index for the Southern Hemisphere. Geophys. Res. Lett., 31, 4, doi:10.1029/2004g1020365.

Raphael, M. N., W. Hobbs, and I. Wainer, 2011: The effect of Antarctic sea ice on the Southern Hemisphere atmosphere during the southern summer. Climate Dyn., 36, 1403-1417, doi:10.1007/s00382-010-0892-1. 
Rayner, N. A., D. E. Parker, E. B. Horton, C. K. Folland, L. V. Alexander, D. P. Rowell, E. C. Kent, and A. Kaplan, 2003: Global analyses of sea surface temperature, sea ice, and night marine air temperature since the late nineteenth century. J. Geophys. Res., 108, 4407, doi:10.1029/2002JD002670.

Risbey, J. S., M. J. Pook, P. C. McIntosh, M. C. Wheeler, and H. H. Hendon, 2009: On the Remote Drivers of Rainfall Variability in Australia. Mon. Wea. Rev., 137, 3233-3253, doi:10.1175/2009mwr2861.1.

Roff, G., D. W. J. Thompson, and H. Hendon, 2011: Does increasing model stratospheric resolution improve extended-range forecast skill? Geophys. Res. Lett., 38, L05809, doi:10.1029/2010GL046515.

Rogers, J. C., and H. van Loon, 1982: Spatial Variability of Sea Level Pressure and $500 \mathrm{mb}$ Height Anomalies over the Southern Hemisphere. Mon. Wea. Rev., 110, 1375-1392, doi:10.1175/1520-0493(1982)110<1375:svoslp >2.0.co;2.

Salby, M. L., E. A. Titova, and L. Deschamps, 2011: Rebound of Antarctic ozone. Geophys. Res. Lett., 38, L09702, doi:10.1029/2011g1047266.

Salby, M. L., E. A. Titova, and L. Deschamps, 2012: Changes of the Antarctic ozone hole: Controlling mechanisms, seasonal predictability, and evolution. J. Geophys. Res., 117, D10111, doi:10.1029/2011jd016285.

Santer, B. D., T. M. L. Wigley, J. S. Boyle, D. J. Gaffen, J. J. Hnilo, D. Nychka, D. E. Parker, and K. E. Taylor, 2000: Statistical significance of trends and trend differences in layer-average atmospheric temperature time series. J. Geophys. Res., 105, 7337-7356, doi:10.1029/1999jd901105. 
892 Schneider, D. P., C. Deser, and T. T. Fan, 2015: Comparing the Impacts of Tropical SST

893

894

895

896

897

898

899

900

901

902

903

904

905

906

907

908

909

910

911

912 Variability and Polar Stratospheric Ozone Loss on the Southern Ocean Westerly Winds. J. Climate, 28, 9350-9372, doi:10.1175/jcli-d-15-0090.1.

Seviour, W. J. M., S. C. Hardiman, L. J. Gray, N. Butchart, C. MacLachlan, and A. A. Scaife, 2014: Skillful Seasonal Prediction of the Southern Annular Mode and Antarctic Ozone. J. Climate, 27, 7462-7474, doi:10.1175/jcli-d-14-00264.1.

Seviour, W. J. M., D. W. Waugh, L. M. Polvani, G. J. P. Correa, and C. I. Garfinkel, 2017: Robustness of the Simulated Tropospheric Response to Ozone Depletion. J. Climate, 30, 2577-2585, doi:10.1175/jcli-d-16-0817.1.

Shaw, T. A., J. Perlwitz, N. Harnik, P. A. Newman, and S. Pawson, 2011: The Impact of Stratospheric Ozone Changes on Downward Wave Coupling in the Southern Hemisphere. J. Climate, 24, 4210-4229, doi:10.1175/2011jcli4170.1.

Sheshadri, A., and R. A. Plumb, 2016: Sensitivity of the surface responses of an idealized AGCM to the timing of imposed ozone depletion-like polar stratospheric cooling. Geophys. Res. Lett., 43, 2330-2336, doi:10.1002/2016g1067964.

Smith, K. L., and L. M. Polvani, 2017: Spatial patterns of recent Antarctic surface temperature trends and the importance of natural variability: lessons from multiple reconstructions and the CMIP5 models. Climate Dyn., 48, 2653-2670, doi:10.1007/s00382-016-3230-4.

Solomon, S., 1999: Stratospheric ozone depletion: A review of concepts and history. Rev. Geophys., 37, 275-316, doi:10.1029/1999rg900008. 
913 Solomon, S., D. J. Ivy, D. Kinnison, M. J. Mills, R. R. Neely, III, and A. Schmidt, 2016:

914 Emergence of healing in the Antarctic ozone layer. Science, 353, 269-274,

915 doi:10.1126/science.aae0061.

916 Son, S.-W., and Coauthors, 2008: The Impact of Stratospheric Ozone Recovery on the

917

918

919

920

921

922

923

924

925

926

927

928

929

930

931

932

933
Southern Hemisphere Westerly Jet. Science, 320, 1486-1489, doi:10.1126/science.1155939.

Son, S.-W., A. Purich, H. H. Hendon, B.-M. Kim, and L. M. Polvani, 2013: Improved seasonal forecast using ozone hole variability? Geophys. Res. Lett., 40, 6231-6235, doi:10.1002/2013g1057731.

Stone, K. A., O. Morgenstern, D. J. Karoly, A. R. Klekociuk, W. J. French, N. L. Abraham, and R. Schofield, 2016: Evaluation of the ACCESS - chemistry-climate model for the Southern Hemisphere. Atmos. Chem. Phys., 16, 2401-2415, doi:10.5194/acp-16-24012016.

Stone, K. A., and Coauthors, 2017: Observing the Impact of Calbuco Volcanic Aerosols on South Polar Ozone Depletion in 2015. J. Geophys. Res., 122, 11862-11879, doi:10.1002/2017JD026987.

Thompson, D. W. J., and S. Solomon, 2002: Interpretation of recent Southern Hemisphere climate change. Science, 296, 895-899, doi:10.1126/science.1069270.

Thompson, D. W. J., M. P. Baldwin, and S. Solomon, 2005: Stratosphere-troposphere coupling in the Southern Hemisphere. J. Atmos. Sci., 62, 708-715, doi:10.1175/jas3321.1. 
934 Thompson, D. W. J., S. Solomon, P. J. Kushner, M. H. England, K. M. Grise, and D. J. Karoly, 2011: Signatures of the Antarctic ozone hole in Southern Hemisphere surface climate change. Nat. Geosci., 4, 741-749, doi:10.1038/ngeo1296.

Trenberth, K. E., 1979: Interannual Variability of the $500 \mathrm{mb}$ Zonal Mean Flow in the Southern Hemisphere. Mon. Wea. Rev., 107, 1515-1524, doi:10.1175/15200493(1979)107<1515:ivotmz>2.0.co;2.

Trenberth, K. E., 1997: The Definition of El Niño. Bull. Amer. Meteor. Soc., 78, 2771-2777, doi:10.1175/1520-0477(1997)078<2771:tdoeno>2.0.co;2.

Turner, J., J. S. Hosking, T. J. Bracegirdle, T. Phillips, and G. J. Marshall, 2017: Variability and trends in the Southern Hemisphere high latitude, quasi-stationary planetary waves. Int. J. Climatol., 37, 2325-2336, doi:10.1002/joc.4848.

van Ommen, T. D., and V. Morgan, 2010: Snowfall increase in coastal East Antarctica linked 946 with southwest Western Australian drought. Nat. Geosci., 3, 267-272, doi:10.1038/ngeo 761 .

World Meteorological Organization (WMO), 2014: Scientific Assessment of Ozone Depletion: 2014, 416 pp.

Zubiaurre, I., and N. Calvo, 2012: The El Niño-Southern Oscillation (ENSO) Modoki signal in the stratosphere. J. Geophys. Res., 117, 15, doi:10.1029/2011jd016690.

952

953

954

955

956 


\section{LIST OF TABLES}

958 Table 1. Correlations coefficients for detrended November ozone and detrended summer 959 surface temperature over Eastern Australia from 1979-2004 in the WACCM

960 experiments. The correlations are calculated after first concatenating the 5 (3)

961

962 ensemble members from the uncoupled (coupled) experiment, apart from the volcano analysis where the years corresponding to the El Chichón (1982) and 963 Mount Pinatubo (1991) eruptions were removed from the model ensemble 964 mean. Correlations for the concatenated members are also shown; refer to Fig. 5 for the ensemble mean values.

966 An asterisk indicates correlations statistically significant at the $90 \%$ confidence 967 level, italics for the 95\% level and bold for the 99\% level. A two-tailed $t$ test is used to test significance with the degrees of freedom reduced based on the lag1 autocorrelation. 43

970

Table 2. Correlation coefficients for detrended November ozone with the detrended 972 summer Niño 3.4 index, for the period 1979-2004. An asterisk indicates correlations statistically significant at the $90 \%$ level, italics for the $95 \%$ level and bold for the $99 \%$ level..

976 Table 3. Same as Table 2, but for the correlation between November ozone and the summer SAM. .45

Table 4. Correlation coefficients for detrended summer ENSO and summer SAM indices 
1979-2004. An asterisk indicates correlations that are statistically significant at the $90 \%$ level, italics for the $95 \%$ level and bold for the $99 \%$ level. . . . . . . 46

983

984 Table A1. Standard deviation of the ozone index over 26 years of data, for the observed 985 Halley and NIWA-BS datasets and the three uncoupled, coupled, GHG1960 and 986 ODS1960 WACCM ensemble members. 1979-2004 for September-December 987 and 1980-2005 for January-April. .

988

989

Table A2. Standard deviation of the SAM index over 26 years of data for each three-month 990 overlapping period, for the Marshall (2003) SAM index and the three uncoupled and coupled WACCM ensemble members. 1979-2004 for periods beginning in 992 September-December and 1980-2005 for January-April. . . . . . . . . . . 48

993

994

995

996

997

998

999

1000

1001

1002

1003

1004

1005 
TABLE 1. Correlation coefficients for detrended November ozone and detrended

1009 summer surface temperature over Eastern Australia from 1979-2004 in the WACCM

1010 experiments. The ensemble mean and ENSO were removed from the 5 (3) concatenated

1011 ensemble members from the uncoupled (coupled) experiment, and the two major volcanic

1012 eruptions (El Chichón (1982) and Mount Pinatubo (1991)) were removed from the model

1013 ensemble mean. Correlations for the concatenated members are also shown; refer to Fig. 5 for

1014 the ensemble mean values.

1015 An asterisk indicates correlations statistically significant at the $90 \%$ confidence level, 1016 italics for the $95 \%$ level and bold for the 99\% level. A two-tailed $t$ test is used to test significance 1017 with the degrees of freedom reduced based on the lag-1 autocorrelation.

Correlations between ozone and surface temperature

\begin{tabular}{lll}
\hline Concatenated members & Uncoupled & $\mathbf{0 . 4 1}$ \\
& Coupled & 0.11 \\
Ensemble mean removed from concatenated members & Uncoupled & 0.03 \\
& Coupled & -0.05 \\
ENSO removed from concatenated members & Uncoupled & $\mathbf{0 . 3 4}$ \\
& Coupled & 0.16 \\
Volcanic eruptions removed from ensemble mean & Uncoupled & $\mathbf{0 . 6 7}$ \\
& Coupled & 0.08 \\
\hline
\end{tabular}

1018 
TABLE 2. Correlation coefficients for detrended November ozone with the detrended

1029 summer Niño 3.4 index, for the period 1979-2004. An asterisk indicates correlations

1030 statistically significant at the $90 \%$ level, italics for the $95 \%$ level and bold for the $99 \%$ level.

\begin{tabular}{lll}
\hline Observations & Halley & 0.11 \\
& NIWA-BS & 0.10 \\
WACCM & Uncoupled & 0.26 \\
& Coupled & -0.03
\end{tabular}

1031

1032

1033

1034

1035

1036

1037

1038

1039

1040

1041

1042 
1050 summer SAM.

\begin{tabular}{lll}
\hline \hline Observations & Halley & -0.33 \\
& NIWA-BS & -0.40 \\
WACCM & Uncoupled & $\mathbf{- 0 . 3 0}$ \\
& Coupled & $\mathbf{- 0 . 3 9}$ \\
\hline
\end{tabular}

1051

1052

1053

1054

1055

1056

1057

1058

1059

1060

1061

1062

1063 
1069 indices with detrended Eastern Australian summer surface temperature, for the period 1979-

1070 2004. An asterisk indicates correlations that are statistically significant at the $90 \%$ level, italics

1071 for the $95 \%$ level and bold for the $99 \%$ level.

\begin{tabular}{llc}
\hline \hline \multicolumn{2}{c}{ Surface temperature correlated with ENSO and SAM } \\
\hline ENSO & Observations & 0.39 \\
& Uncoupled & $\mathbf{0 . 4 7}$ \\
& Coupled & $\mathbf{0 . 6 1}$ \\
\hline SAM & Observations & -0.24 \\
& Uncoupled & $\mathbf{- 0 . 4 1}$ \\
& Coupled & -0.03 \\
CCSM4 & 0.10 \\
CESM1-CAM5 & $\mathbf{- 0 . 3 6}$ \\
\hline
\end{tabular}

1072

1073

1074

1075

1076

1077

1078

1079 
1080

1081

1082 TABLE A1. Standard deviation of the ozone index over 26 years of data, for the 1083 observed Halley and NIWA-BS datasets and the three uncoupled, coupled, GHG1960 and 1084 ODS1960 WACCM ensemble members. 1979-2004 for September-December and 1980-2005 1085 for January-April.

\begin{tabular}{|c|c|c|c|c|c|c|c|c|c|c|}
\hline & & & Sep & Oct & Nov & $\overline{\text { Dec }}$ & Jan & Feb & Mar & Apr \\
\hline \multirow[t]{2}{*}{ Observations } & Halley & & 19.61 & 33.14 & 43.86 & 21.86 & 8.40 & 8.53 & 10.41 & 14.11 \\
\hline & NIWA-BS & & 23.67 & 33.48 & 34.33 & 13.95 & 6.05 & 6.45 & 6.64 & 7.63 \\
\hline \multirow[t]{12}{*}{ WACCM } & Uncoupled & rlilp1 & 24.38 & 31.88 & 32.92 & 22.90 & 11.36 & 9.43 & 8.36 & 8.81 \\
\hline & & r2ilp1 & 27.13 & 32.47 & 29.12 & 22.07 & 12.71 & 10.19 & 9.35 & 8.79 \\
\hline & & r3ilp1 & 29.37 & 33.14 & 28.58 & 22.03 & 13.41 & 9.31 & 8.53 & 8.15 \\
\hline & Coupled & rlilp1 & 22.75 & 30.63 & 27.48 & 18.52 & 9.76 & 8.16 & 7.60 & 6.36 \\
\hline & & r2ilp1 & 21.99 & 28.71 & 28.08 & 18.06 & 9.71 & 8.30 & 7.35 & 6.76 \\
\hline & & r3ilp1 & 22.97 & 25.98 & 27.11 & 20.30 & 11.72 & 8.00 & 6.72 & 8.37 \\
\hline & GHG1960 & r1ilp1 & 23.74 & 29.79 & 27.64 & 19.00 & 10.79 & 8.75 & 7.92 & 7.93 \\
\hline & & r2ilp1 & 23.60 & 27.47 & 28.05 & 17.47 & 9.83 & 7.82 & 7.86 & 6.91 \\
\hline & & r3ilp1 & 25.83 & 28.47 & 26.81 & 22.17 & 12.68 & 9.66 & 10.04 & 9.98 \\
\hline & ODS 1960 & r1ilp1 & 13.44 & 14.06 & 13.55 & 8.15 & 6.90 & 5.74 & 5.52 & 6.70 \\
\hline & & r2ilp1 & 15.52 & 16.32 & 15.74 & 9.83 & 7.64 & 6.74 & 7.96 & 8.70 \\
\hline & & r3ilp1 & 15.24 & 16.78 & 14.78 & 7.21 & 6.53 & 5.29 & 6.23 & 7.72 \\
\hline
\end{tabular}

1086

1087

1088

1089

1090

1091 
TABLE A2. Standard deviation of the SAM index over 26 years of data for each three1098 month overlapping period, for the Marshall (2003) SAM index and the three uncoupled and 1099 coupled WACCM ensemble members. 1979-2004 for periods beginning in September-

1100 December and 1980-2005 for January-April.

\begin{tabular}{|c|c|c|c|c|c|c|c|c|c|c|}
\hline & & & SON & OND & NDJ & DJF & JFM & FMA & MAM & AMJ \\
\hline Observations & & & 1.26 & 1.29 & 1.15 & 1.10 & 1.00 & 1.02 & 1.05 & 1.06 \\
\hline \multirow[t]{6}{*}{ WACCM } & Uncoupled & rlilp1 & 1.46 & 1.49 & 1.33 & 1.29 & 0.83 & 0.82 & 1.07 & 1.06 \\
\hline & & r2ilp1 & 1.08 & 1.12 & 1.06 & 1.15 & 1.14 & 1.17 & 1.09 & 1.02 \\
\hline & & r3ilp1 & 1.23 & 1.29 & 1.19 & 1.11 & 1.19 & 1.32 & 1.24 & 1.11 \\
\hline & Coupled & r1ilp1 & 1.13 & 1.09 & 1.07 & 1.11 & 1.27 & 1.13 & 1.27 & 1.14 \\
\hline & & r2ilp1 & 1.06 & 1.05 & 1.05 & 1.16 & 0.93 & 0.79 & 0.72 & 1.16 \\
\hline & & r3ilp1 & 0.99 & 1.01 & 1.08 & 1.07 & 0.83 & 0.93 & 1.16 & 1.13 \\
\hline
\end{tabular}

1101

1102

1103

1104

1105

1106

1107

1108

1109

1110 


\section{LIST OF FIGURES}

1112 Fig. 1. Time series (1979-2004) of the November ozone index for the first ensemble member of WACCM (a) uncoupled (REF-C1) and (b) coupled (REF-C2) experiments, and the detrended November ozone index for (c) uncoupled and (d) coupled. Years with high/low polar cap $\left(63-90^{\circ} \mathrm{S}\right)$ averaged TCO are identified as those that exceed $+/$ - one standard deviation (red/blue horizontal lines). Note that $+/$ - one standard deviation is calculated across the three members

Fig. 2. Lag correlation between the detrended ozone index and detrended SAM index for each 3-month overlapping period, for 1979-2004 (1980-2005 for the ozone index in JanuaryApril). (a) Halley ozone $\left(75^{\circ} \mathrm{S}, 25^{\circ} \mathrm{W}\right)$ and (b) NIWA-BS ozone $\left(63-90^{\circ} \mathrm{S}\right)$ with the Marshall (2003) SAM index, and (c), (d), (e) and (f) TCO (63-90 ${ }^{\circ}$ S) and SAM from WACCM uncoupled, coupled, GHG1960 and ODS1960 experiments, respectively. The horizontal axis indicates the ozone index month. The vertical axis shows the 3 -month overlapping average SAM, e.g. September ozone correlated with SAM in +0 SON, +1 OND, +2 NDJ, +3 DJF and +4 JFM. The correlation coefficients that are statistically significant at the $90 \%, 95 \%$ and $99 \%$ confidence levels are bound by yellow, green and white contour lines, respectively. A two-tailed $t$ test is used to test significance, with the degrees of freedom reduced based on the lag-1 autocorrelation coefficient.

Fig. 3. As in Fig. 2, but for the lagged correlation between the ozone index and Eastern Australia surface temperature. Two surface temperature datasets are used for the observations: ERA-Interim for (a) with Halley ozone and (c) NIWA-BS ozone, and 
1136 Fig. 4. Correlation coefficients between detrended November ozone and detrended summer surface temperatures (1979-2004) for (a) Halley ozone and (b) NIWA-BS ozone with ERA-Interim surface temperatures, and (c) and (d) ozone and surface temperatures from WACCM uncoupled and coupled experiments, respectively. Hatching indicates correlations that are statistically significant at the $95 \%$ level. .57

Fig. 5. Correlation coefficients for detrended November ozone and detrended Eastern Australia summer surface temperature (1979-2004). Column 1 shows the observations: ERAInterim surface temperature and Halley (red cross; $75^{\circ} \mathrm{S}, 26^{\circ} \mathrm{W}$ ), Syowa (yellow; $69^{\circ} \mathrm{S}$, $39^{\circ} \mathrm{E}$ ), South Pole (blue; $90^{\circ} \mathrm{S}, 25^{\circ} \mathrm{W}$ ), and NIWA-BS (green; $63-90^{\circ} \mathrm{S}$ ) ozone. Columns 2 and 3 show the WACCM uncoupled and coupled experiments, respectively. Individual ensemble members are shown with a cross and the ensemble mean with a circle. Columns 4, 5 and 6 show all available members for the CCMI models in three groups: CCMI-REF-C1, CCMI-REF-C2-uncoupled where SSTs and sea ice are prescribed from another climate model, and CCMI-REF-C2-coupled (ACCESS-CCM $=$ red cross, CESM1 CAM4-Chem = blue, CMAM = magenta, EMAC-L47MA = grey, EMAC-L90MA = dark green, GEOSCCM = purple, MRI-ESM = pale green, NIWA-

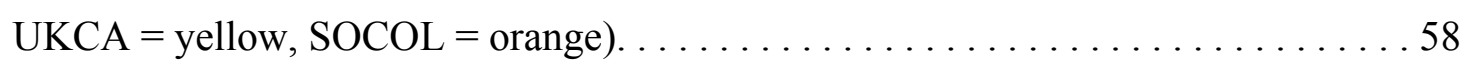

Fig. 6. Time-height evolution of the composite differences (high - low ozone) between the years with the highest and lowest (magnitude exceeds one standard deviation; number of years indicated at the top left of each column) polar cap $\left(63-90^{\circ} \mathrm{S}\right)$ averaged November ozone values (1979-2004) for vertically resolved polar cap average geopotential height [m]. Left: composite differences for WACCM uncoupled 
experiment; right: coupled experiment. Hatching indicates differences that are statistically significant at the $95 \%$ level.

1163 Fig. 7. Composite differences (high - low ozone) in summer between the years with the highest and lowest (magnitude exceeds one standard deviation; number of years indicated at the top left of each column) November ozone values (1979-2004). (a, b) Surface temperature [K]. (c, d) Zonal wind at $500 \mathrm{hPa}\left[\mathrm{m} \mathrm{s}^{-1}\right]$. (e, f) Sea level pressure (SLP) [Pa]. Left: composite differences for Halley ozone; right: for NIWA-BS ozone. Hatching indicates differences that are statistically significant at the $95 \%$ level. . . . 61

Fig. 8. As in Fig. 7, but for WACCM. Left: composite differences for the uncoupled experiment; right: for coupled experiment. 62

Fig. 9. Correlation coefficients between detrended Eastern Australia summer surface temperatures and detrended summer SSTs and SLP (1979-2004) for (a, b) observations, and (c, d) uncoupled and (e, f) coupled WACCM experiments. Hatching indicates correlations that are statistically significant at the $95 \%$ level. 63

Fig. 10. As in Figs. 7 and 8, but for the composite differences (high - low SAM) in summer between the positive and negative phases of the summer SAM (when the magnitude exceeds one standard deviation; number of years indicated at the top left of each column). (a, d, g) observations, and (b, e, h) uncoupled and (c, f, i) coupled WACCM experiments 
Uncoupled

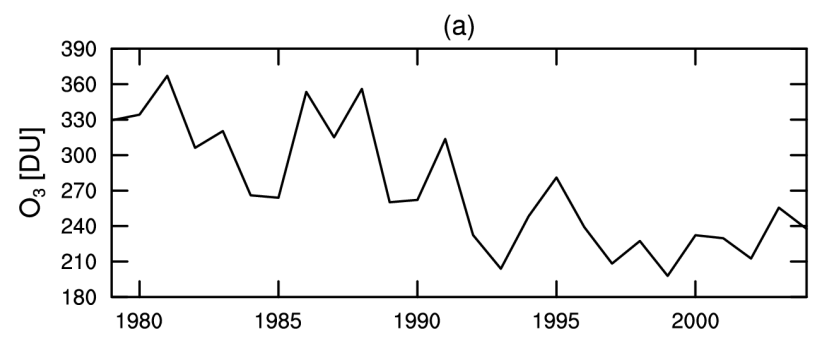

(c)

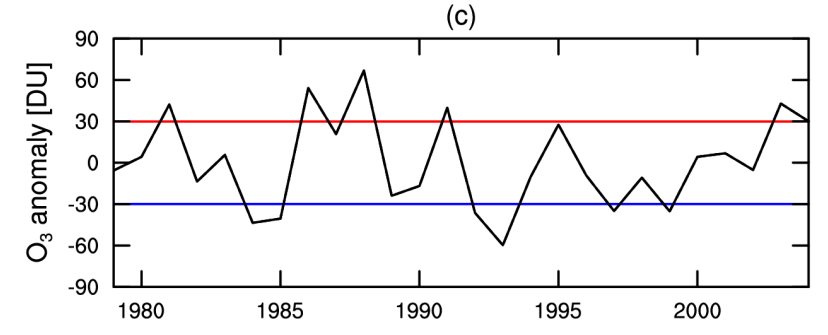

\section{Coupled}

(b)

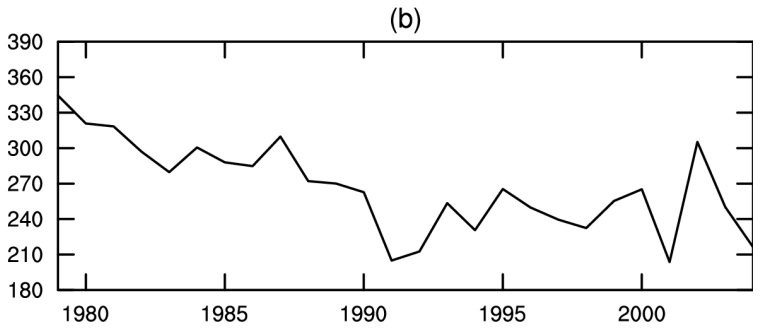

(d)

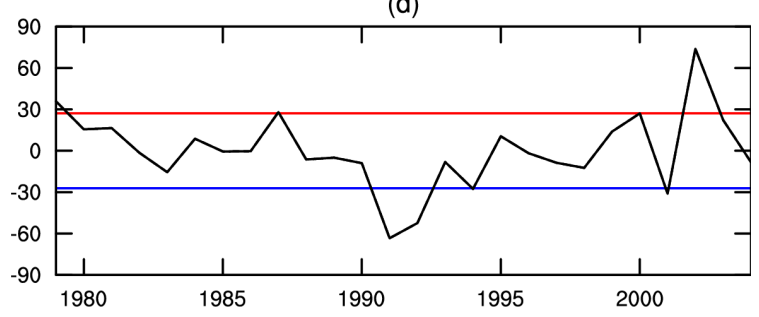

FIG. 1. Time series (1979-2004) of the November ozone index for the first ensemble

1193 member of WACCM (a) uncoupled (REF-C1) and (b) coupled (REF-C2) experiments, and the

1194 detrended November ozone index for (c) uncoupled and (d) coupled. Years with high/low polar

1195 cap $\left(63-90^{\circ} \mathrm{S}\right)$ averaged TCO are identified as those that exceed $+/$ - one standard deviation

1196 (red/blue horizontal lines). Note that $+/$ - one standard deviation is calculated across the three 1197 members. 

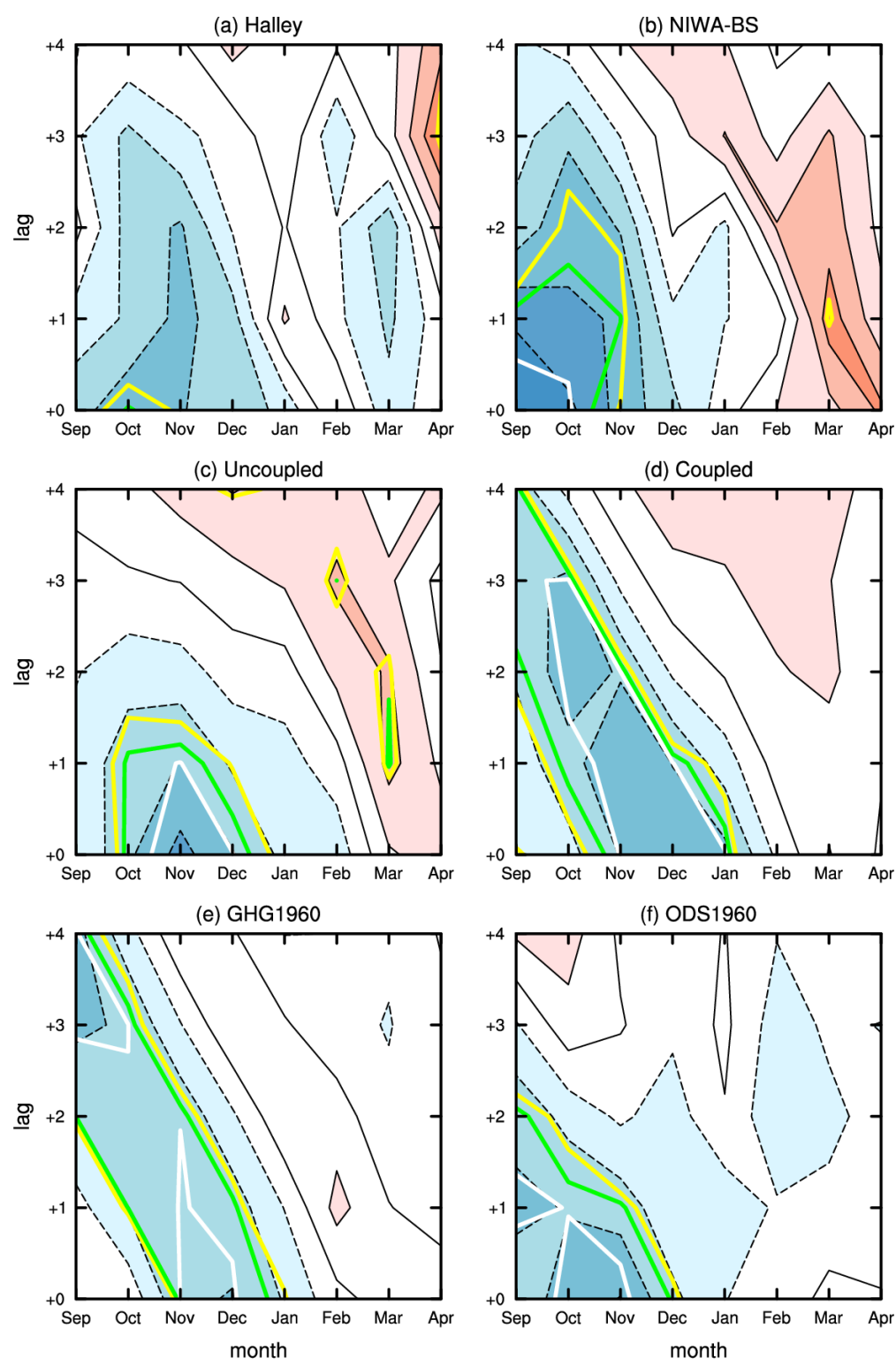

FIG. 2. Lag correlation between the detrended ozone index and detrended SAM index

1200 for each 3-month overlapping period, for 1979-2004 (1980-2005 for the ozone index in

1201 January-April). (a) Halley ozone $\left(75^{\circ} \mathrm{S}, 25^{\circ} \mathrm{W}\right)$ and (b) NIWA-BS ozone $\left(63-90^{\circ} \mathrm{S}\right)$ with the

1202 Marshall (2003) SAM index, and (c), (d), (e) and (f) TCO (63-90 ${ }^{\circ}$ S) and SAM from WACCM

1203 uncoupled, coupled, GHG1960 and ODS1960 experiments, respectively. The horizontal axis

1204 indicates the ozone index month. The vertical axis shows the 3 -month overlapping average

1205 SAM, e.g. September ozone correlated with SAM in +0 SON,+1 OND, +2 NDJ, +3 DJF and +4 JFM. The correlation coefficients that are statistically significant at the $90 \%, 95 \%$ and $99 \%$ 
1207 confidence levels are bound by yellow, green and white contour lines, respectively. A two1208 tailed $t$ test is used to test significance, with the degrees of freedom reduced based on the lag-1 1209 autocorrelation coefficient. 

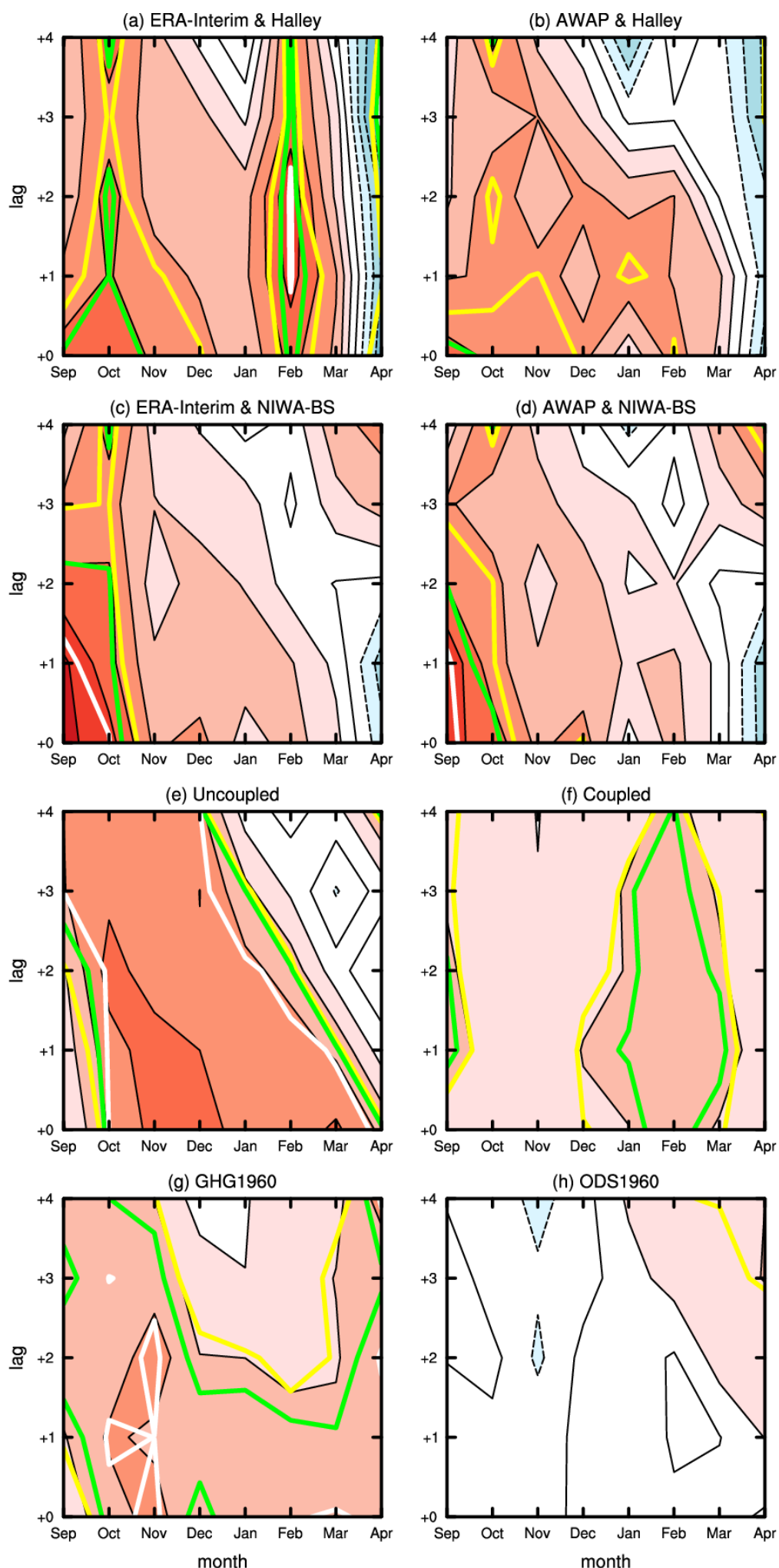

FIG. 3. As in Fig. 2, but for the lagged correlation between the ozone index and Eastern

1212 Australia surface temperature. Two surface temperature datasets are used for the observations: 
1213 ERA-Interim for (a) with Halley ozone and (c) NIWA-BS ozone, and AWAP with (b) Halley

1214 and (d) NIWA-BS.

1215

1216

1217

1218

1219

1220

1221

1222

1223

1224

1225

1226

1227

1228

1229

1230

1231

1232

1233

1234

1235

1236

1237 
(a) Halley

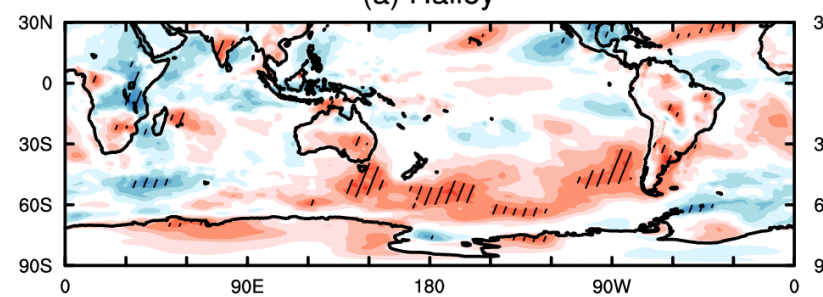

(c) Uncoupled

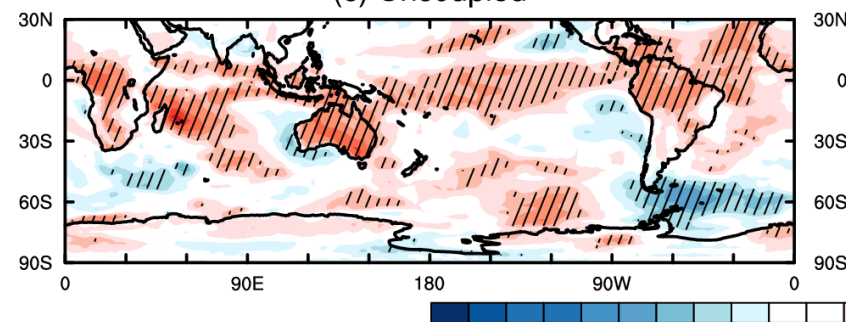

(b) NIWA-BS

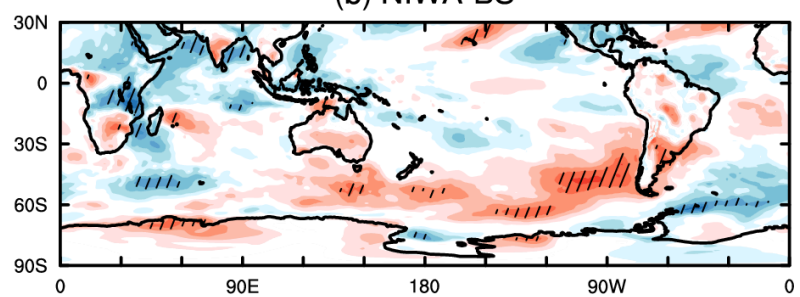

(d) Coupled

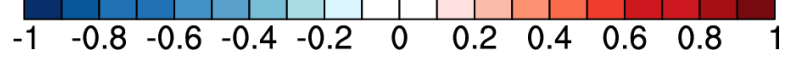

FIG. 4. Correlation coefficients between detrended November ozone and detrended

1246 summer surface temperatures (1979-2004) for (a) Halley ozone and (b) NIWA-BS ozone with

1247 ERA-Interim surface temperatures, and (c) and (d) ozone and surface temperatures from

1248 WACCM uncoupled and coupled experiments, respectively. Hatching indicates correlations

1249 that are statistically significant at the $95 \%$ level. 


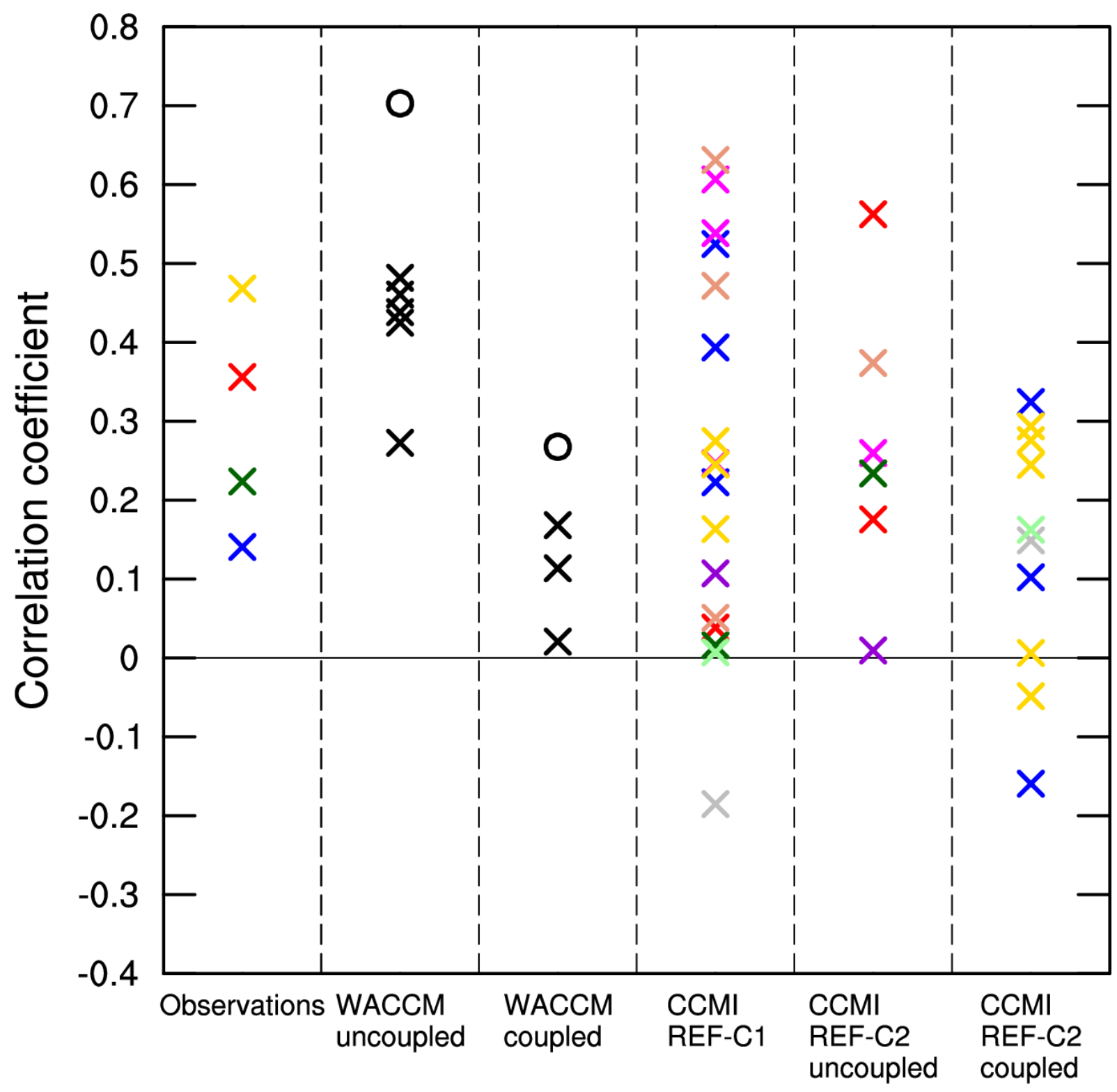

FIG. 5. Correlation coefficients for detrended November ozone and detrended Eastern

1258 Australia summer surface temperature (1979-2004). Column 1 shows the observations: ERA-

1259 Interim surface temperature and Halley (red cross; $\left.75^{\circ} \mathrm{S}, 26^{\circ} \mathrm{W}\right)$, Syowa (yellow; $69^{\circ} \mathrm{S}, 39^{\circ} \mathrm{E}$ ),

1260 South Pole (blue; $90^{\circ} \mathrm{S}, 25^{\circ} \mathrm{W}$ ), and NIWA-BS (green; 63-90 $\mathrm{S}$ ) ozone. Columns 2 and 3 show

1261 the WACCM uncoupled and coupled experiments, respectively. Individual ensemble members

1262 are shown with a cross and the ensemble mean with a circle. Columns 4,5 and 6 show all

1263 available members for the CCMI models in three groups: CCMI-REF-C1, CCMI-REF-C2-

1264 uncoupled where SSTs and sea ice are prescribed from another climate model, and CCMI-REF-

1265 C2-coupled $($ ACCESS-CCM = red cross, CESM1 CAM4-Chem = blue, CMAM = magenta, 
1266 EMAC-L47MA = grey, EMAC-L90MA = dark green, GEOSCCM = purple, MRI-ESM = pale

1267 green, NIWA-UKCA = yellow, SOCOL = orange).

1268

1269

1270

1271

1272

1273

1274

1275

1276

1277

1278

1279

1280

1281

1282

1283

1284

1285

1286

1287

1288

1289

1290 
(a) Uncoupled

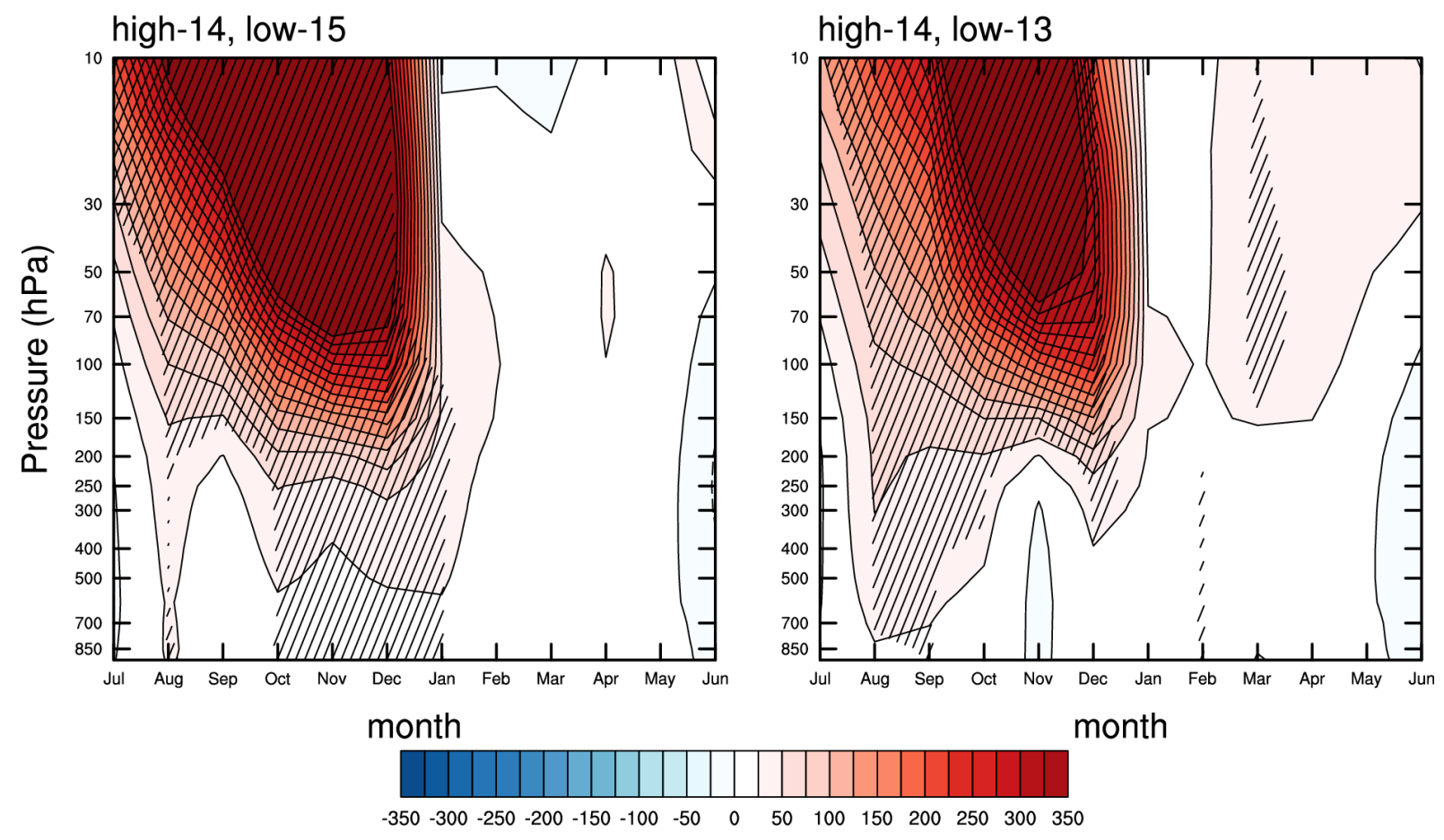

FIG. 6. Time-height evolution of the composite differences (high - low ozone) between

1297 the years with the highest and lowest (magnitude exceeds one standard deviation; number of

1298 years indicated at the top left of each column) polar cap (63-90 $\mathrm{S})$ averaged November ozone

1299 values (1979-2004) for vertically resolved polar cap average geopotential height [m]. Left:

1300 composite differences for WACCM uncoupled experiment; right: coupled experiment.

1301 Hatching indicates differences that are statistically significant at the $95 \%$ level. 
Halley

high-4, low-3 $\quad$ (a) surface $T$

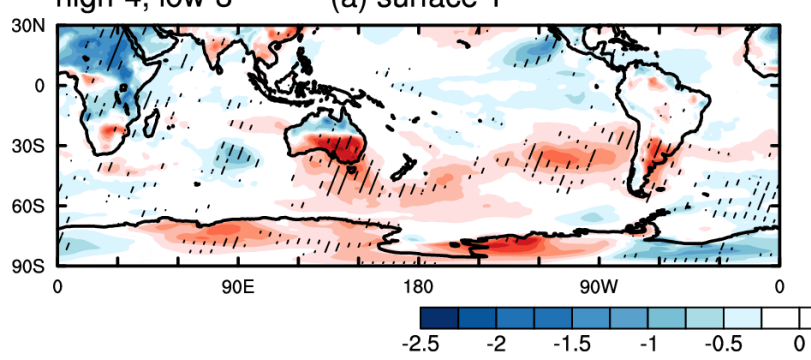

(c) U500

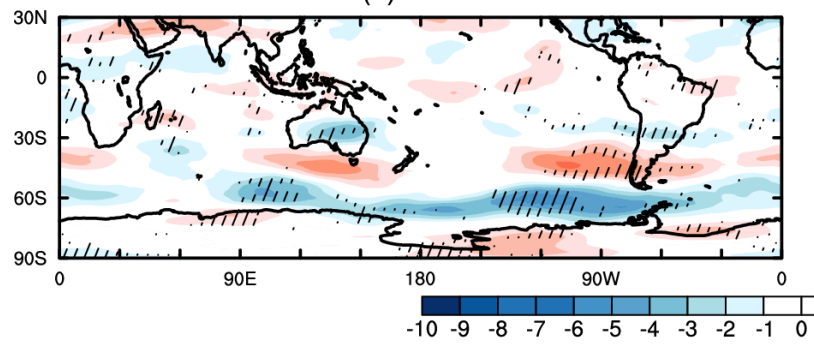

(e) SLP

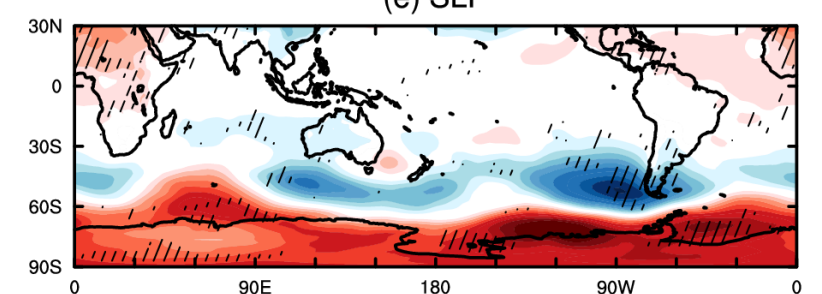

180

\section{NIWA-BS}

high-3, low-4

(b) surface $T$

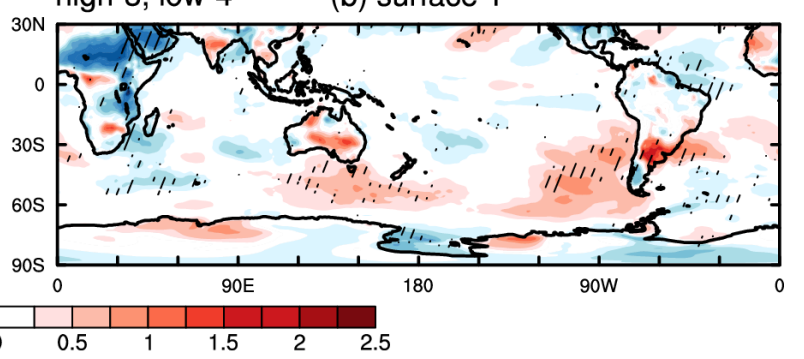

(d) U500

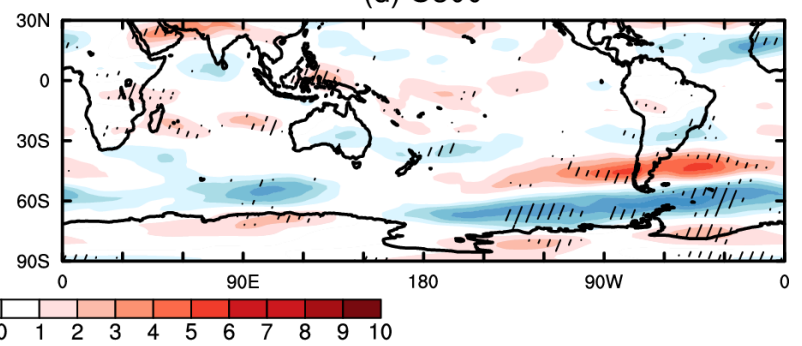

(f) SLP

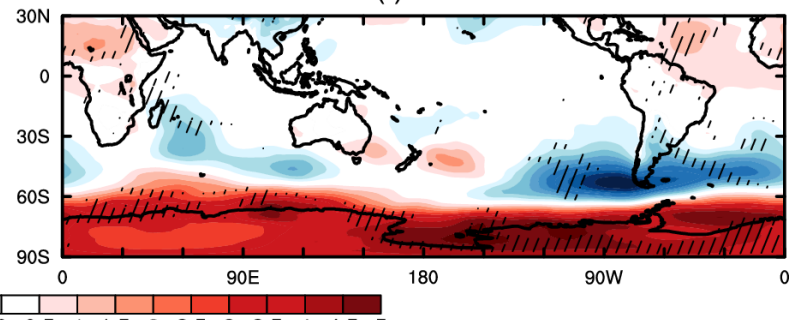

FIG. 7. Composite differences (high - low ozone) in summer between the years with

1307 the highest and lowest (magnitude exceeds one standard deviation; number of years indicated

1308 at the top left of each column) November ozone values (1979-2004). (a, b) Surface temperature

$1309[\mathrm{~K}] .(\mathrm{c}, \mathrm{d})$ Zonal wind at $500 \mathrm{hPa}\left[\mathrm{m} \mathrm{s}^{-1}\right]$. (e, f) Sea level pressure (SLP) [hPa]. Left: composite

1310 differences for Halley ozone; right: for NIWA-BS ozone. Hatching indicates differences that

1311 are statistically significant at the $95 \%$ level. 


\section{Uncoupled}

(a) surface $T$

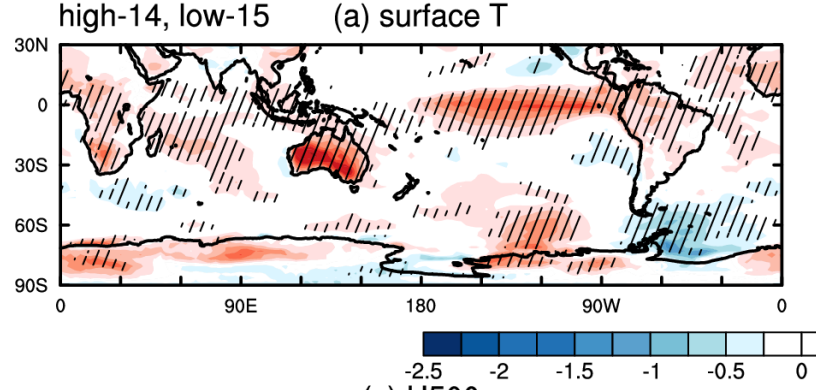

(c) $\cup 500$

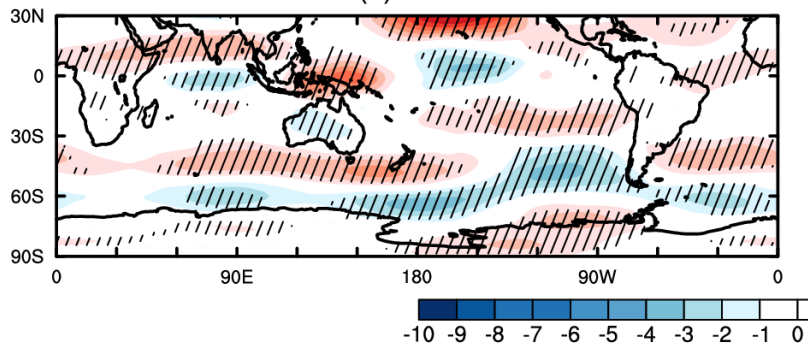

(e) SLP

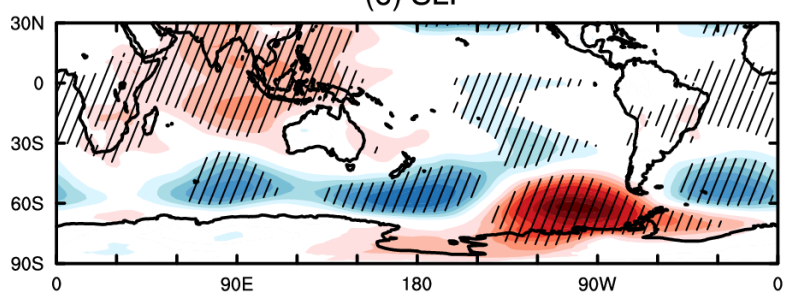

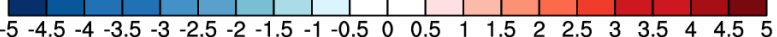

\section{Coupled}

high-14, low-13 $\quad$ (b) surface $T$

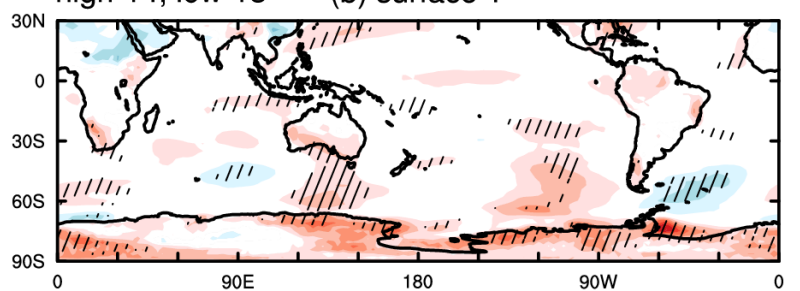

(d) U500

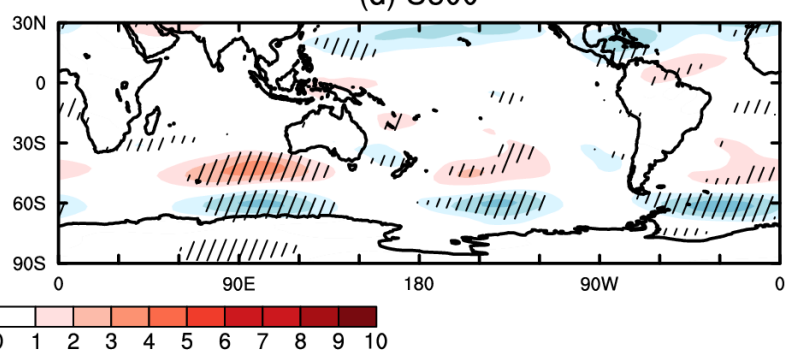

(f) SLP

FIG. 8. As in Fig. 7, but for WACCM. Left: composite differences for the uncoupled

1318 experiment; right: for coupled experiment. 
SST

(a) Observations

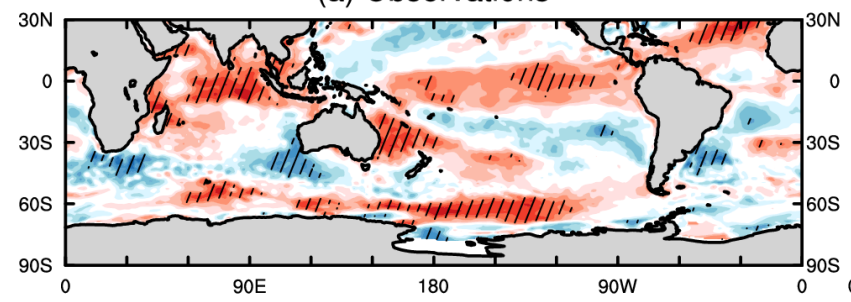

(c) Uncoupled

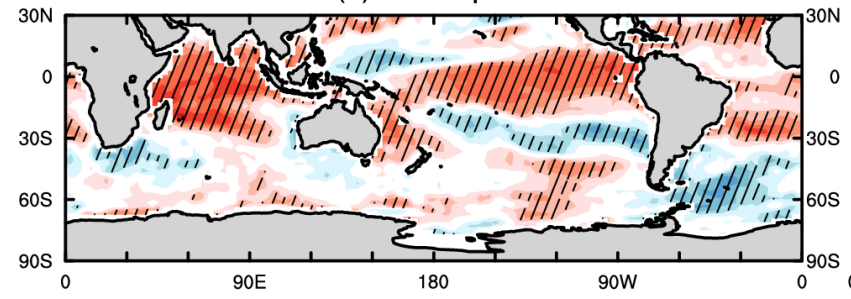

(e) Coupled

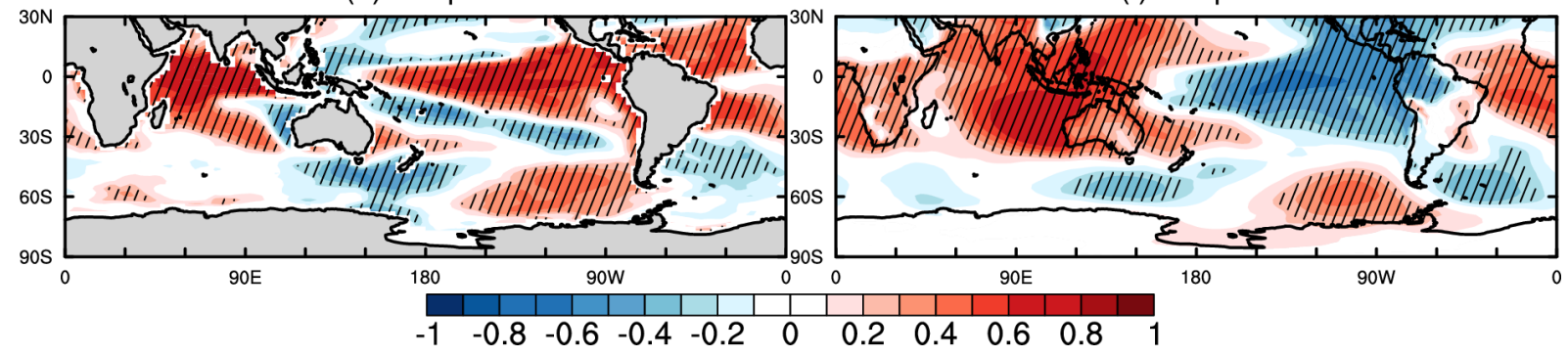

(b) Observations

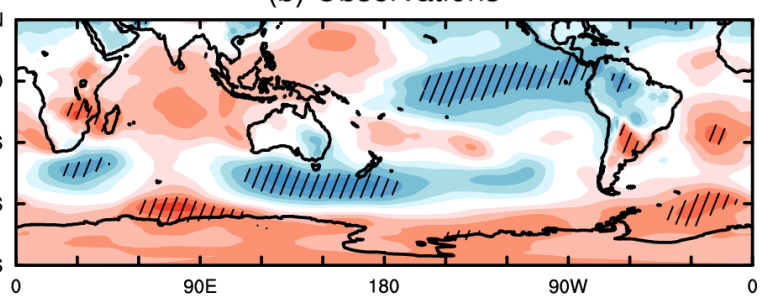

(d) Uncoupled

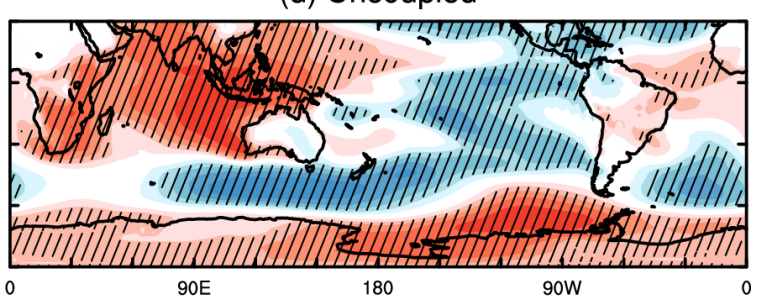

(f) Coupled

1331 temperatures and detrended summer SSTs and SLP (1979-2004) for (a, b) observations, and (c,

1332 d) uncoupled and (e, f) coupled WACCM experiments. Hatching indicates correlations that are

1333 statistically significant at the $95 \%$ level. 

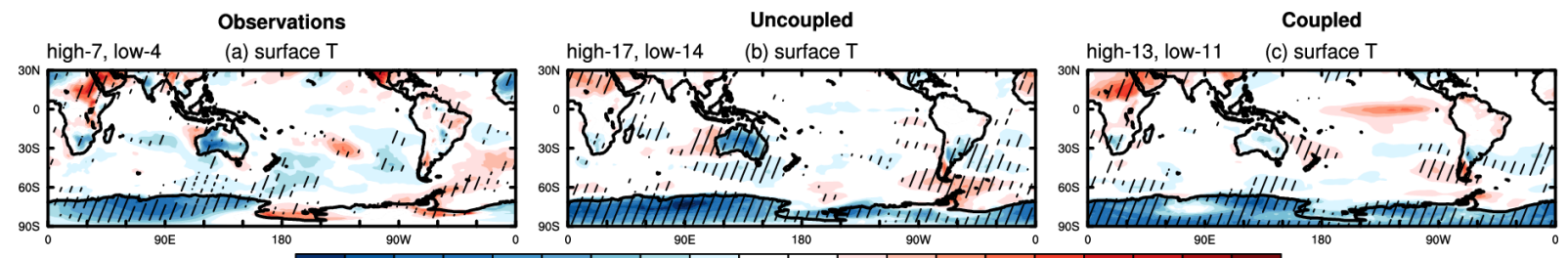

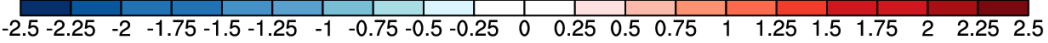
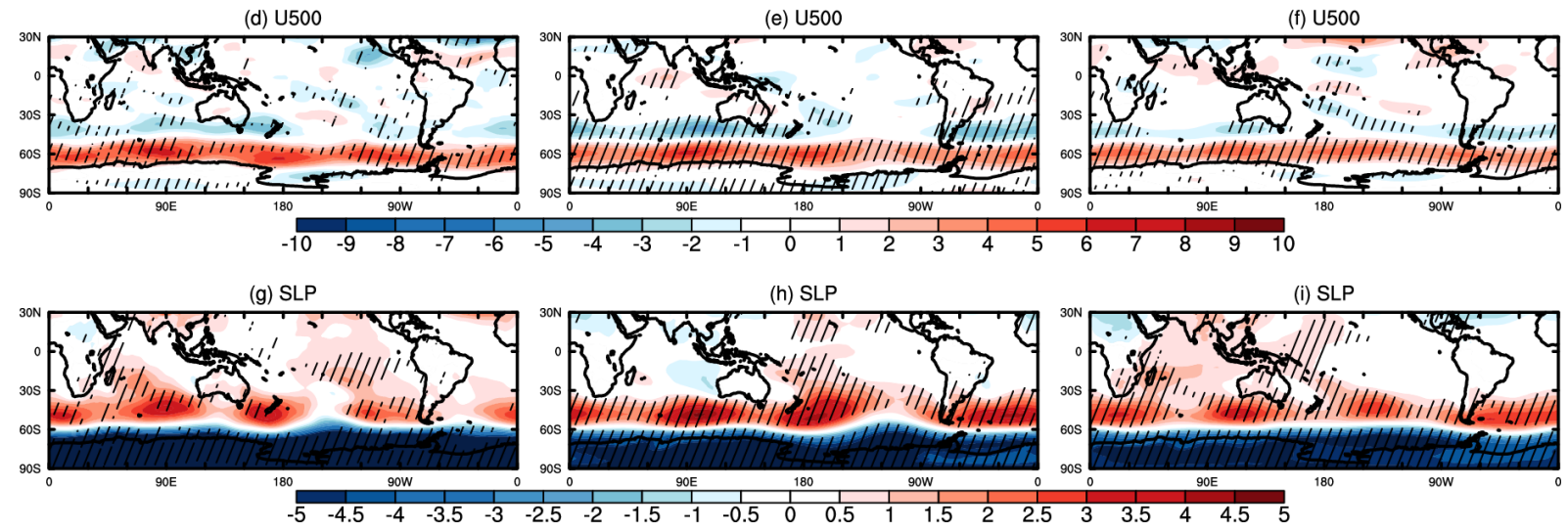

1344

FIG. 10. As in Figs. 7 and 8, but for the composite differences (high - low SAM) in

1346 summer between the positive and negative phases of the summer SAM (when the magnitude

1347 exceeds one standard deviation; number of years indicated at the top left of each column). (a,

$1348 \mathrm{~d}, \mathrm{~g})$ observations, and (b, e, h) WACCM uncoupled and (c, f, i) coupled experiments. 